Review

\title{
Low-Temperature Induced Enhancement of Photoelectric Performance in Semiconducting Nanomaterials
}

\author{
Liyun $\mathrm{Wu}^{1,2}$, Yun $\mathrm{Ji}^{2,3}$, Bangsen Ouyang ${ }^{2,3}$, Zhengke $\mathrm{Li}^{1, *}$ and Ya Yang ${ }^{2,3,4, *}$ \\ 1 School of Material Science and Engineering, Sun Yat-Sen University, Guangzhou 510275, China; \\ Wuly37@mail2.sysu.edu.cn \\ 2 Center for Excellence in Nanoscience, Beijing Key Laboratory of Micro-Nano Energy and Sensor, \\ Beijing Institute of Nanoenergy and Nanosystems, Chinese Academy of Sciences, Beijing 101400, China; \\ jiyun@binn.cas.cn (Y.J.); ouyangbangsen@binn.cas.cn (B.O.) \\ 3 School of Nanoscience and Technology, University of Chinese Academy of Sciences, Beijing 100049, China \\ 4 Center on Nanoenergy Research, School of Physical Science and Technology, Guangxi University, \\ Nanning 530004, China \\ * Correspondence: lizhengke@mail.sysu.edu.cn (Z.L.); yayang@binn.cas.cn (Y.Y.)
}

check for

updates

Citation: Wu, L.; Ji, Y.; Ouyang, B.; Li, Z.; Yang, Y. Low-Temperature Induced Enhancement of

Photoelectric Performance in Semiconducting Nanomaterials. Nanomaterials 2021, 11, 1131. https://doi.org/10.3390/ nano11051131

Academic Editor:

Andres Castellanos-Gomez

Received: 7 April 2021

Accepted: 24 April 2021

Published: 27 April 2021

Publisher's Note: MDPI stays neutral with regard to jurisdictional claims in published maps and institutional affiliations.

\begin{abstract}
The development of light-electricity conversion in nanomaterials has drawn intensive attention to the topic of achieving high efficiency and environmentally adaptive photoelectric technologies. Besides traditional improving methods, we noted that low-temperature cooling possesses advantages in applicability, stability and nondamaging characteristics. Because of the temperaturerelated physical properties of nanoscale materials, the working mechanism of cooling originates from intrinsic characteristics, such as crystal structure, carrier motion and carrier or trap density. Here, emerging advances in cooling-enhanced photoelectric performance are reviewed, including aspects of materials, performance and mechanisms. Finally, potential applications and existing issues are also summarized. These investigations on low-temperature cooling unveil it as an innovative strategy to further realize improvement to photoelectric conversion without damaging intrinsic components and foresee high-performance applications in extreme conditions.
\end{abstract}

Keywords: temperature dependence; photoelectric; photodetector; solar cell

\section{Introduction}

To meet the emergent requirement of the development of sustainable and clean energy, solar energy, recognized as the best potential alternative to fossil-fuel power, has been intensively investigated regarding its effective harvesting, conversion and storage in past decades [1-9]. One of the major developments lies in the mature utilization of nanoscale materials, such as two-dimensional materials [10,11] and quantum dots [12]. However, the advent of the photoelectric device also raises concerns regarding adaptivity to diversified environments, such as outer space or other extreme environments. Differing from the widely researched performance at normal temperature condition, the investigations on extreme temperature conditions, especially low temperature, are insufficient for completing the underlying physical mechanism and applying it to practical use. There are a handful of reports showing decreased performance at low temperature. These weakening phenomena caused by lowering temperature are ascribed to many causes including frozen carrier diffusion [13], reduced absorption [14], interfacial ion accumulation [15], phase transition [16] and radiative [17] and nonradiative [18] recombination. However, there are also many reports that low-temperature operation is not a restriction but an enhancement to overall photoelectric performance, ranging from low-dimension materials to nanocrystals. The effectiveness of the cooling method on these devices not only provides a strategy for constructing photoelectric devices under extreme conditions but also reveals the potential of cooling as an innovative and efficacious method for improving optoelectronic performance. 
It is worth noting that small drops in temperature will also cause visible improvement in photoelectric performance [19-21]. No matter the need, in applications or in theoretical research, relevant reports on the cooling method is in urgent need of systematic summary and guidance.

To realize improvements through low-temperature cooling, the underlying function mechanism deserves investigation. Similar to coupling effects or surface modification [22-26], the cooling method functions without changing composition or inherent structures. Moreover, compared with these traditional methods, cooling's enhanced effects have unique advantages in applicability, stability and nondestructive characteristics. In view of the existing theories, the general temperature-dependent methods can be divided into three aspects: materials, devices and performances, shown in Figure 1. Temperature variation first directly functions on materials, inducing fluctuations in energy level [27-29], carrier motions [30], density of traps/carriers [31] and crystal structure transition [32]. For cooling-enhanced materials, regulation in energy levels causes changes in absorption [28], barrier height [33] and so on [34,35], then influences photon absorption and charge transportation. Some intrinsic characteristics of carriers are reported to show huge enhancement from cooling, including mobility [36], diffusion length [37] and corresponding densities [38]. For specific materials, structure transition [39] has been observed in a low-temperature range, providing more potential for cooling regulation. When the above phenomena integrated with devices, the cooling-enhanced properties in devices can be classified into absorption [40], carrier diffusion and recombination [41,42], resistance [43], photoconductivity [44], permittivity [45], interfaces and defects [46] and can improve the overall performance of both photodetectors and solar cells. The full mechanism is based on temperature-dependent optical and electrical properties, thus the emergence of the utilization of the cooling method, which possesses many advantages over conventional improvement methods and also possesses benefits to reliable photoelectric application in harsh environments.

Here, we summarize the cooling-enhanced effect on the photoelectric process in various nanoscale semiconductors from near room temperature $(300 \mathrm{~K})$ to liquid nitrogen temperature (77 K). First, low-temperature-enhanced photoelectric parameters, materials and their corresponding devices' structures are classified for further analysis with the underlying photoelectric mechanism. On this basis, the cooling-enhanced photoelectric performance and corresponding physical mechanism are demonstrated in different photoelectric processes. In this section, we also symmetrically discuss the related characteristics of cryogenic-enhanced optoelectronic devices from carrier movement to device optimization. Finally, the future opportunities and potential application of cooling-enhancing effects in optoelectronics are discussed for further scientific research and practical utilization. 


\section{Temperature Dependence: From Low Temperature to RT}

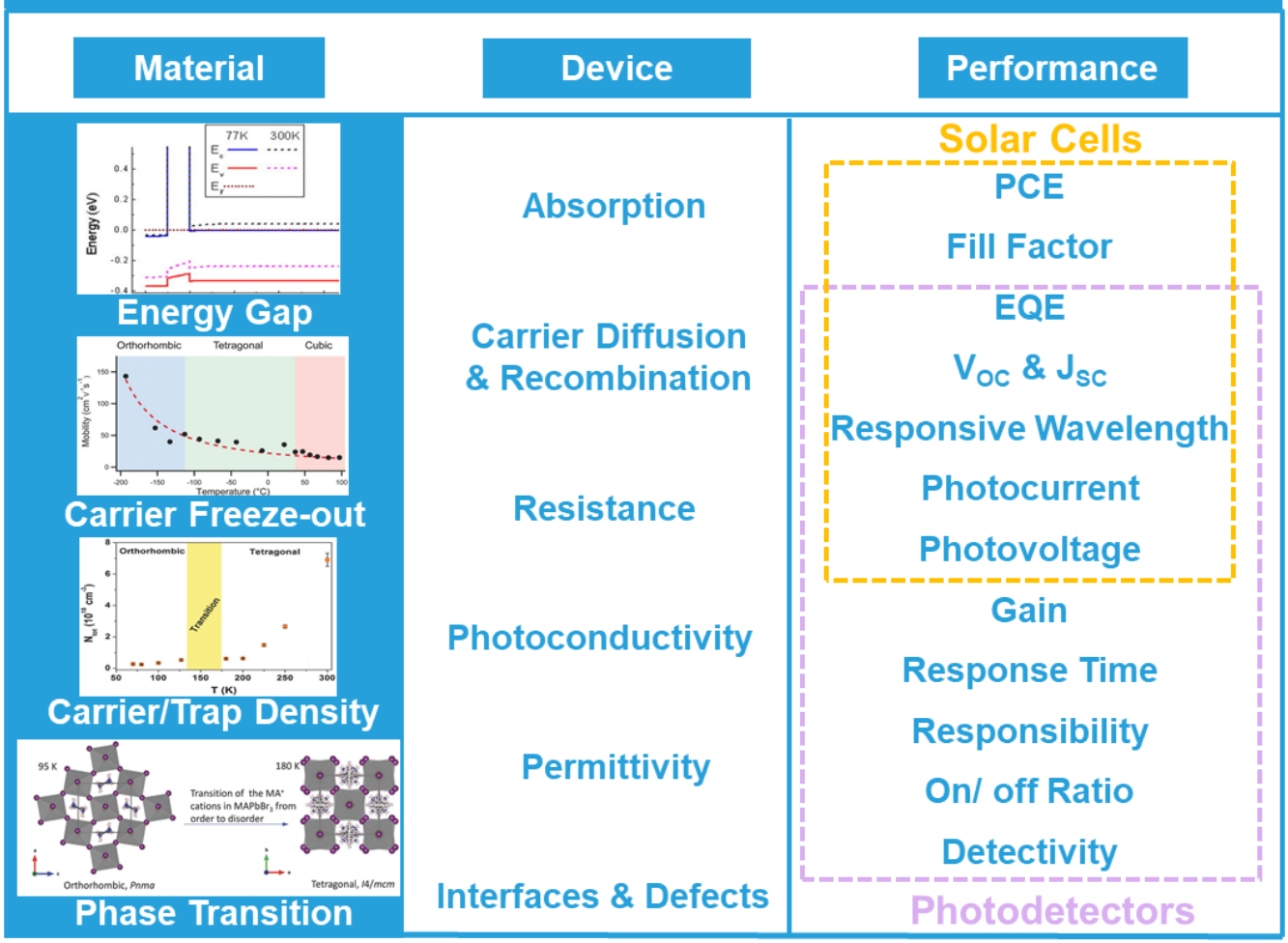

Figure 1. Temperature-dependent effect on photoelectric devices including materials, devices and performances. All images reproduced with permission: "Bandgap" (adapted from [29], with permission from the American Institute of Physics, 2014). "Carrier freeze-out" (adapted from [30], with permission from Wiley-VCH, 2015). "Carrier/Trap Density" (adapted from [31], with permission from Wiley-VCH, 2017). "Phase Transition" (adapted from [32], with permission from Wiley-VCH, 2018).

\section{Materials with Cooling-Enhanced Effects}

The influence of temperature on the photoelectric process is closely related to nanomaterials and their structures. The working range of the cooling method includes nanomaterials from elemental semiconductors to organic-inorganic complexes. The reported works on cryogenic-enhanced optoelectrical performance are based on various photoelectric structures, summarized as photovoltaic photodiodes, photoconductors, phototransistors and photogating transistors, as depicted on the right side of Figure 2. 


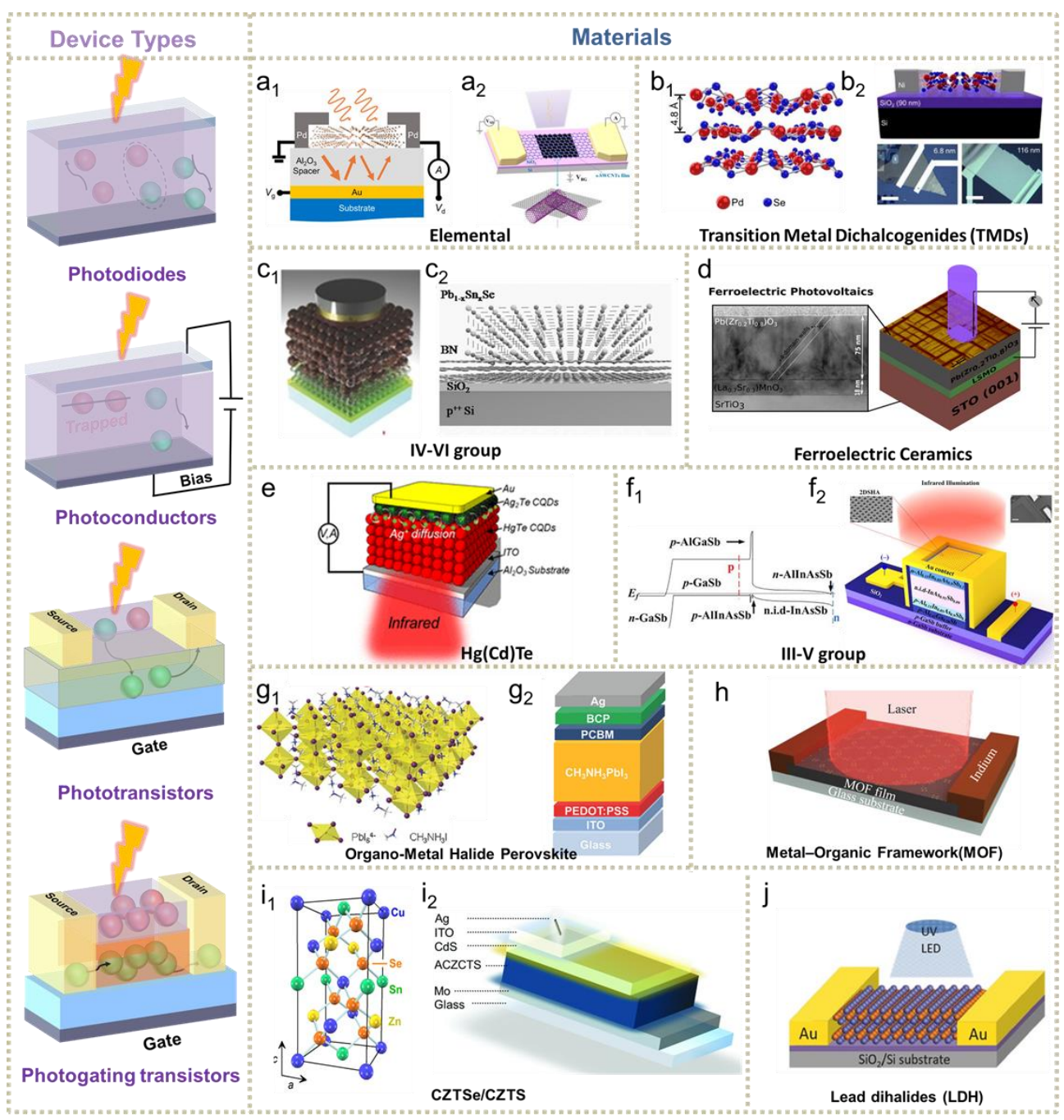

Figure 2. Fundamental devices configuration and materials categories with cooling-enhanced photoelectric performance. (a) Elemental semiconductors. (a) Tellurium nanoflakes (adapted from [47], with permission from the American Chemical Society, 2018). ((a) Graphene (adapted from [48], with permission from the American Institute of Physics, 2018). (b) Transition metal dichalcogenide (adapted from [49], with permission from the American Institute of Physics, 2019). ( $\mathbf{c}_{1}$ ) PbS (adapted from [50], with permission from Wiley-VCH, 2014). ( $\left.\mathbf{c}_{2}\right) \mathrm{Pb}_{1-\mathrm{x}} \mathrm{Sn}_{\mathrm{x}} \mathrm{Se}$ (adapted from [51], with permission from Wiley-VCH, 2015). (d) Ferroelectric ceramics (adapted from [52], with permission from the American Chemical Society, 2020). (e) $\mathrm{Hg}(\mathrm{Cd}) \mathrm{Te}$ (adapted from [53], with permission from the

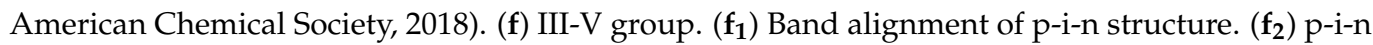
structure (both adapted from [54], with permission from the American Institute of Physics, 2018). (g) Organo-metal halide perovskite. $\left(\mathbf{g}_{1}\right)$ Crystal structure (adapted from [55], with permission from Wiley-VCH, 2016). ( $\left.\mathbf{g}_{2}\right)$ Planar perovskite solar cells (adapted from [31], with permission from WileyVCH, 2017). (h) Metal-organic framework, reproduced with permission [20], from Wiley-VCH, 2020). (i) CZTSe/CZTS solar cells. (i $\mathbf{i}_{1}$ ) Crystal structure (adapted from [56], with permission from Elsevier, 2017). (i $\left.\mathbf{i}_{2}\right)$ CZTS planar solar cells (adapted from [57], with permission from Wiley-VCH, 2018). (j) Lead dihalides (adapted from [58], with permission from Wiley-VCH, 2017).

In photovoltaic photodiodes, effective electron-hole pairs are activated by absorbed phonons, and then separated by built-in electric fields to transport to specific electrodes for collection. In this case, Ohmic contact, Schottky contact, the p-n junction or more complex p-i-n junction are required driving forces. Solar cells [13,59,60], III-V group infrared photodetectors [61-66], as well as most ferroelectric ceramic [67-71]-based devices, have evolved from photovoltaic photodiodes. Another popular photoelectric device is 
the photoconductor, which responds to illumination through photoconductance changes. By sacrificing the self-powered characteristic, photoconductors have superiorities in gain (G) $[72,73]$ by applied bias voltage due to bias-enhanced carriers' lifetime. In cryogenic enhancement tests, the photoconductive type is widely employed in two-dimensional materials [74] and quantum dots (QDs) [33,75-77]. The main problem faced by photoconductive devices is comparatively higher dark current. The device consists of terminals played by source, drain and gate, and photoactive channel to lower dark current and increase photoresponse in phototransistor structure. When integrated with high mobility materials, two-dimensional materials [20,78,79] prefer to adopt phototransistor structure. As a special example in phototransistor devices, photogating phototransistors stem from the photogating effect, which modulates devices' conductance by phonon-induced traps. Several graphene-based structures $[48,80]$ have been explored as cooling enhanced their photogating performance. Here, we focus on photoelectric devices with application in solar cells and photodetectors, especially infrared (IR) detectors consisting of near-infrared (NIR, 0.7-1 $\mu \mathrm{m}$ ), short-wavelength infrared (SWIR, 1-3 $\mu \mathrm{m}$ ), mid-wavelength infrared (MWIR, 3-5 $\mu \mathrm{m}$ ) and long-wavelength infrared (LWIR, 8-14 $\mu \mathrm{m}$ ) photodetectors. On the basis of devices' structures, numerous materials, simply classified in the right part of Figure 2, varying from elemental to inorganic-organic hybrid semiconductors, have been researched for low-temperature photoelectric performance. As shown in Figure 2a, the elemental materials are represented by graphene [33,81-83], black phosphorus [84,85], silicon [86], tellurium [47] and boron [87]. Since these 2D materials prefer the photoconductive mechanism, the utilization of the cooling method mainly influenced their photoconductive characteristics for devices' performance. Two-dimensional transition-metal dichalcogenides (TMDs) [88,89]-based photodetectors have also been intensely explored in visible and near-IR spectrum. They are competitive in high stability, high photoresponsivity and quick response. Zhang et al. studied $\mathrm{PdSe}_{2}$-based photodetectors' performance from $77 \mathrm{~K}$ to $300 \mathrm{~K}$ and found higher effective electron mobilities up to $520 \mathrm{~cm}^{2} \mathrm{~V}^{-1} \mathrm{~s}^{-1}$ at $77 \mathrm{~K}$, further improving photoresponse [49]. In addition to elemental quantum dots, IV-VI group materials, represented by $\mathrm{PbS}[50,90,91], \mathrm{PbSe}[19,51]$ and $\mathrm{PbTe}$ [92], have been tested for low-temperature photodetection on solar cells (Figure 2c). Speirs et al. found PbS quantum dots solar cells' FF and $\mathrm{V}_{\mathrm{OC}}$ increased when cooling to $230 \mathrm{~K}$ without sacrificing current, resulting from temperature-dependent reverse saturation current [93]. Chusnutdinow et al. explored PbTe-based photodetectors that performed better as $2.7 \times 10^{10}$ Jones under low temperature for raised carrier intensity and mobility [92]. Weng et al. prepared a $\mathrm{CdS} / \mathrm{PbSe}$ photovoltaic photodetector and then discovered that the cooling-enhanced cutoff wavelength expanded to near $7.0 \mu \mathrm{m}$ due to the band energy component being changed by the temperature [19]. As depicted in Figure 2d, the unique photovoltaic effect in ferroelectric materials like $\mathrm{BiFeO}_{3}[70,94-98]$ and $\mathrm{Pb}(\mathrm{Zr}, \mathrm{Ti}) \mathrm{O}_{3}[52,99]$ inspired research on temperature-influenced bulk photovoltaic performance. The research of III-Vs and $\mathrm{HgCdTe}$-based photodetectors significantly pushed forward the development of infrared sensing systems. HgCdTe-type IR photodetectors were predicted to be more qualified than both MWIR and LWIR for their long S-R lifetime near 4000 us [100], compared with IV-IVs. Zhu et al. investigated the temperature-dependent relationship between low frequency noise and dark current in SWIR, MWIR and LWIR [101]. Due to the competition between diffusion and generation-recombination (G-R) current, declining temperature can effectively reduce dark current. Another newly emerging $\mathrm{Hg}(\mathrm{Cd}) \mathrm{Te}$-type infrared photodetector is HgTe QDs for the MWIR range. Ackerman et al. constructed HgTe CQDs that performed $0.56 \mathrm{~A} \mathrm{~W}^{-1}$ at $150 \mathrm{~K}$ for low-temperature enhanced diffusion [102]. For the III-Vs group, as illustrated in Figure 2f, the p-i-n structure is commonly adopted to reduce noise current with higher barrier height. Apart from designing these complex structures, cryogenic cooling methods have been widely proven to be effective in weakening dark current in III-Vs photodetectors, which will be further discussed in Section 3.2.2. It is necessary to emphasize that the intensive investigation of organic-metal halide perovskite solar cells (Figure 2g), where the organic part refers to methylammonium (MA) 
cations and formamidinium (FA) cations, gives in-depth insight to the mechanisms of the temperature-dependent photovoltaic effect from material to device, deeply discussed in Section 3.3. As a tailorable electric material, MOFs with semiconducting features are capable of functioning as active elements in the photoelectric process. Recently, Arora et al. reported a novel $\mathrm{Fe}_{3}(\mathrm{THT})_{2}\left(\mathrm{NH}_{4}\right)_{3} \mathrm{MOF}-$ based photodetector presenting an improved photoresponse with declining temperature [20]. Authors attributed these phenomena to suppressed thermally activated carriers under $77 \mathrm{~K}$. CZTS or CZTSe is another promising thin-film material for solar cells owing to its tunable energy gap and low-effective charge masses [56]. Hadke et al. characterized the temperature-dependent behavior $\mathrm{V}_{\mathrm{OC}}$ of several CZTS devices and discovered that all of them increase with decreasing temperature [57], resembling other photovoltaic cells $[86,93,103,104]$. Similar to TMDs, LDHs are newly developed photoconductive 2D materials with superiority in low dark current and ultrahigh photoresponse. As a representative $\mathrm{LDH}$ material, $\mathrm{PbF}_{2-\mathrm{x}} \mathrm{I}_{\mathrm{x}}$ has been reported with cooling-enhanced photodetection performance caused by less phonon scattering under low temperature [58]. It is worth noting that low-temperature enhanced effects have been reported on the above popular optoelectronic materials, which is especially beneficial to low-dimension semiconductors.

\section{Low-Temperature Enhancement in Photoelectric Performance}

The interplay between temperature and the photoelectric process varies along with the specific design of devices. We divided low-temperature-enhanced performance into three parts to analyze the specific function of cooling effects: common physical parameters represented by absorption, photodetector performance, and solar-cell performances. Moreover, the related formulas of temperature-dependent photoelectric parameters are listed in Table 1.

Table 1. Photoelectric parameters with certain temperature-dependent relationships.

\begin{tabular}{|c|c|c|c|c|}
\hline Parameter & Symbol & Unit & T-Dependent & Ref \\
\hline Bandgap & $\mathrm{E}_{\mathrm{g}}$ & $\mathrm{eV}$ & $E_{g}=E_{0}-\frac{\alpha T^{2}}{T+\beta}$ & {$[105]$} \\
\hline Diffusion length & $\mathrm{L}_{\mathrm{D}}$ & $\mu \mathrm{m}$ & $\mathrm{L}_{\mathrm{D}(\mathrm{n})}=\sqrt{\frac{\mu \mathrm{k}_{\mathrm{B}} \mathrm{T}}{\mathrm{e} \mathrm{R}_{\text {total }}(\mathrm{n})}}$ & [30] \\
\hline Open circuit voltage & $\mathrm{V}_{\mathrm{oc}}$ & $\mathrm{V}$ & $\mathrm{V}_{\mathrm{OC}}=\frac{\mathrm{nkT}}{\mathrm{e}} \ln \left(\frac{\mathrm{J}_{\mathrm{PH}}}{\mathrm{J}_{\mathrm{o}}}\right)$ & {$[93]$} \\
\hline Reverse saturation current & $\mathrm{J}_{0}$ & $\mathrm{~mA} \mathrm{~cm}^{-2}$ & $\begin{array}{c}\text { Thermionic emission model: } \\
\mathrm{J}_{\mathrm{TE}}=\mathrm{AT}^{2} \exp \left(-\frac{\mathrm{q} \phi_{\mathrm{B}}}{\mathrm{kT}}\right)\left[\exp \left(\frac{\mathrm{qV}}{\mathrm{kT}}-1\right)\right] \\
\quad \text { Diffusion model: } \\
\mathrm{J}_{\text {Diff }}=\mathrm{e} \mu_{\mathrm{e}(\mathrm{h})} \mathrm{N}_{\mathrm{C}(\mathrm{V})} \mathrm{E}_{\mathrm{m}} \exp \left(\frac{-\mathrm{e} \phi_{\mathrm{B}}}{\mathrm{kT}}\right)\end{array}$ & [106] \\
\hline Photoconductivity & $\sigma$ & $\mathrm{S} \mathrm{cm}^{-1}$ & $\begin{array}{c}\text { Variable Range Hopping: } \\
\sigma_{1}=\sigma_{0} \exp \left[-\left(\frac{\mathrm{T}_{0}}{\mathrm{~T}}\right) \frac{1}{4}\right] \\
\text { Nearest Neighbor Hopping: } \\
\sigma_{2}=\left[\frac{\mathrm{v}_{0} \mathrm{e}^{2} \mathrm{c}(1-\mathrm{c})}{\mathrm{kTr}}\right] \exp (-2 \alpha \mathrm{r}) \exp \left(\frac{-\Delta \mathrm{E}}{\mathrm{kT}}\right)\end{array}$ & {$[107,108]$} \\
\hline Recombination rate & $R_{\text {total }}$ & I & $\mathrm{R}_{\text {total }}=-\mathrm{k}_{\text {Auger }} \mathrm{n}^{3}-\mathrm{k}_{\text {bimo }} \mathrm{n}^{2}-\mathrm{k}_{\text {mono }} \mathrm{n}$ & [109] \\
\hline
\end{tabular}

\subsection{Absorption}

Despite photoelectric investigations over past decades, optical properties like absorption are bottlenecks restricting semiconductor candidates in both photodetectors and solar cells. Unlike traditional tuning methods by doping or sensitizing [110-112], coupling effects and surface modification are reported effective without changing nanostructures. However, they are hindered by applicable materials, performance stability and potential damage. The cooling method can compensate for these. In 1967, Varshni proposed a theoretical equation to elucidate the relationship between bandgap and operating temperature based on the theory of electron-phonon interactions and lattice expansion [105]. The full formula is listed in Table 1 where $E_{g}(0)$ is the bandgap of the semiconductor at $0 \mathrm{~K}$, while $\alpha$ and $\beta$ are empirical constants. According to the Varshni equation, the cutoff wavelength of devices based on single semiconductors tends to monotonous blueshift. As shown in Figure 3a, a significant 
blueshift of absorption and a widened bandgap is observed in the $\mathrm{p}-\mathrm{Si} / \mathrm{n}-\mathrm{ZnO}$ heterojunction when starting temperature declines [113]. However, as shown in Figure 3a,b, for both photoluminescence (PL) spectra and absorption spectra, the $\left(\mathrm{FAPbI}_{3}\right)_{0.85}\left(\mathrm{MAPbBr}_{3}\right)_{0.15}$ perovskite thin films show a red-shift trend [39]. Thus, a declined optical bandgap at low temperature is calculated. Similar positive relationships between bandgap and lowering temperature have also been reported in other hybrid perovskite [41,114-116] materials, since the overlapping orbitals of halogens [34] caused reductions in the valence band. Another cause for the broadening spectra of hybrid perovskites is phase transition [117-119] during cooling. Zheng et al. reported the unusual redshift in absorption attributed to phase transition between orthorhombic and tetragonal structures [119]. Moreover, the phenomenon of widening absorption using cryogenic experiments also exists in other materials and structures. Szendrei et al. witnessed a narrowing bandgap along with cooling in PbS nanocrystals [120], consistent with the previously observed size-dependent $\mathrm{dE}_{\mathrm{g}} / \mathrm{dT}$ effect [121] in PbS quantum dots. Black phosphorus $[28,122,123]$ is also observed to have an abnormal temperature-dependent effect. A comprehensive investigation on $\mathrm{n}-\mathrm{CdS} / \mathrm{p}$-PbSe photodetectors found that the cutoff wavelength increases with declining temperature [19]. Authors reasoned that temperature caused the energy band gap of PbSe and CdS mismatching and shifted the band alignment from type II to type I. Likewise, the tuneable band alignment of the $p$ - $n$ junction under temperature intervention has been studied in other structures, such as GaTe- $\mathrm{MoS}_{2}$ [124] and $\mathrm{SnS}_{2} / \mathrm{p}-\mathrm{Si}$ [125].

a

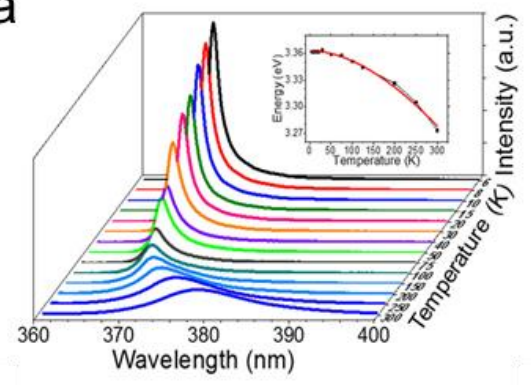

\section{$b$}

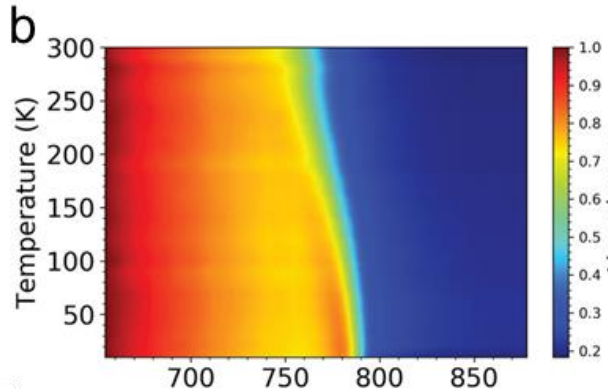

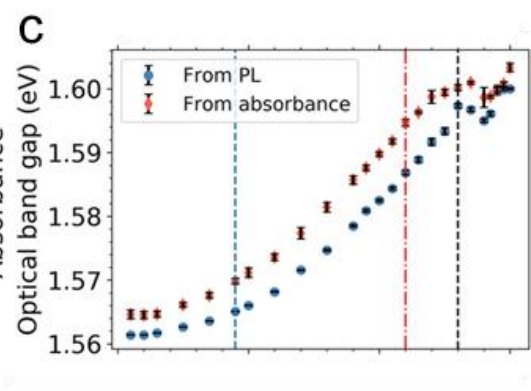

Figure 3. Cooling-enhanced phenomenon of absorption. (a) Temperature-dependent absorption of p-Si/n-ZnO photodetector. Inset: bandgap at various temperatures (adopted from [113], with permission from the American Chemical Society, 2017). (b) Temperature-dependent absorption of perovskite solar cells (adapted from [39], with permission from Wiley-VCH, 2019). (c) Temperature-dependent optical bandgap of perovskite solar cells (adapted from [39], with permission from Wiley-VCH, 2019).

According to the Varshni equation (bandgap equation in Table 1), the absorption coefficient exhibits similar temperature-dependent properties. As illustrated in Figure 3c, even the cutoff wavelength narrowed at lower temperature. The InAs/InAsSb pBn photodetector at cryogenic temperature yielded a higher quantum efficiency at the specific wavelength [126]. Authors proposed a relationship between the absorption coefficient and the temperature-influenced bandgap as:

$$
\alpha(\gamma) \propto\left[\mathrm{E}_{\lambda}-\mathrm{E}_{\mathrm{g}}(\mathrm{T})\right]^{1 / 2}
$$

From this equation, bandgap variation crucially influences the absorption coefficient during cooling. Nevertheless, carriers' diffusion and recombination occupy a crucial place in the absorption coefficient at various temperatures. In the inset picture of Figure 3c, lower quantum efficiency above $220 \mathrm{~K}$ has also resulted from the increased Auger recombination rate and impeded minority diffusion at the higher temperature.

\subsection{Performance of Photodetectors}

Originating from research on light-to-electric conversion, photodetectors are an appealing field in optoelectronics, owing to their applications in optical communication, 
healthy imaging, security monitoring and fire/gas sensing. Similarly to radiation intensity and built-in electric fields, temperature-dependence also exists in the photodetection process, which deeply influences the key processes in light-electric conversion.

In addition to the response spectra discussed above, detectivity and responsivity, as well as quantum efficiency, are the main key figures of merit for photodetectors. Responsivity is proportional to carriers' mobility and the density of photogenerated carriers, shown as:

$$
\mathrm{R}=\frac{\mathrm{q} \tau_{1}}{\mathrm{hv} \tau_{\mathrm{t}}}=\frac{\mathrm{q} \eta \tau_{1} \mu \mathrm{V}}{\mathrm{hvL^{2 }}}
$$

In this formula, $\eta$ represents quantum efficiency, $\tau_{1}$ means the lifetime of photogenerated charges, $\mu$ is mobility, $\mathrm{V}$ and $\mathrm{L}$ are applied bias voltage and channel length, respectively [58]. Likewise, other figures of merit also heavily relied on temperature for intrinsic parameter variation. Nevertheless, considering different photodetection mechanisms, the cooling-enhanced effect functions with different pathways, and we will discuss them in categories.

\subsubsection{Photoconductive Photodetectors}

For the photoconductive mode, photoresponse relies on the process of light absorption in semiconductors raising excess free charges then causing increments in conductivity to realize the sensing process. An additional key figure of merit of photoconductive photodetectors is gain $(\mathrm{G})[3]$, defined as:

$$
\mathrm{G}=\frac{\mathrm{I}_{\mathrm{ph}}}{\mathrm{q}}\left(\phi_{\text {in }} \mathrm{QE}\right)=\mathrm{R} \frac{\mathrm{hc}}{\eta \mathrm{q} \lambda}
$$

where R means responsivity, $\eta, q, \lambda$, h and c represent quantum efficiency, the absolute value of electron, illuminated wavelength, Planck's constant and the velocity of light, respectively. $G$ represents the ratio of the photogenerated carriers collected by the electrode to the photons absorbed by the semiconductor. Likewise, $G$ showed enhanced performance with cooling [127], directly related to carriers' lifetime. The temperature effects on photoconductive photodetectors supposedly originated from photoconductivity, consisting of charges' separation, recombination and diffusion processes. Then, temperature functioned on the overall performance, like on-off ratio, responsivity, G and more. Here, we take several typical parameters of photoconductive photodetectors as an example. In Figure $4 \mathrm{a}$, a typical $J_{\text {dark }}-V$ curve of a boron-nanosheet-based photodetector is measured at temperatures from 20 to $600 \mathrm{~K}$ [87]. As extracted from the slope of the $J-V$ curves, it can be concluded that resistance decreases when temperatures rise. Another report on $\mathrm{Ta}_{2} \mathrm{NiSe}_{5}$ nanoflakes was performed with an enhanced on/off ratio and suppressed dark current, depicted in Figure $4 \mathrm{~b}$. The on/off ratio was significantly enhanced from $\sim 0.1$ at $300 \mathrm{~K}$ to $\sim 60$ at $25 \mathrm{~K}$, realizing reliable signal identification for $808 \mathrm{~nm}$ light. Moreover, the resistance increased to $35 \mathrm{M} \Omega$ at $25 \mathrm{~K}$, meaning dark current was hampered heavily at low temperature. This phenomenon indicates the immense potential of low-temperature operation in improving the on-off ratio and strengthening light-generated current as well as further enhancing responsivity and gain considerably. However, even with cooling the hampered photocurrent, there are photoconductors performing with higher gain and responsivity at low temperature, rather than room temperature, shown in Figure 4c. Zheng et al. synthesized the topological insulator $\mathrm{Sb}_{2} \mathrm{Te}_{3}$ photodetector. The enhanced gain and responsivity are acquired by cooling. Simultaneously reduced photocurrent is resulted from competences of bulk states and surface states at different temperatures [128]. 

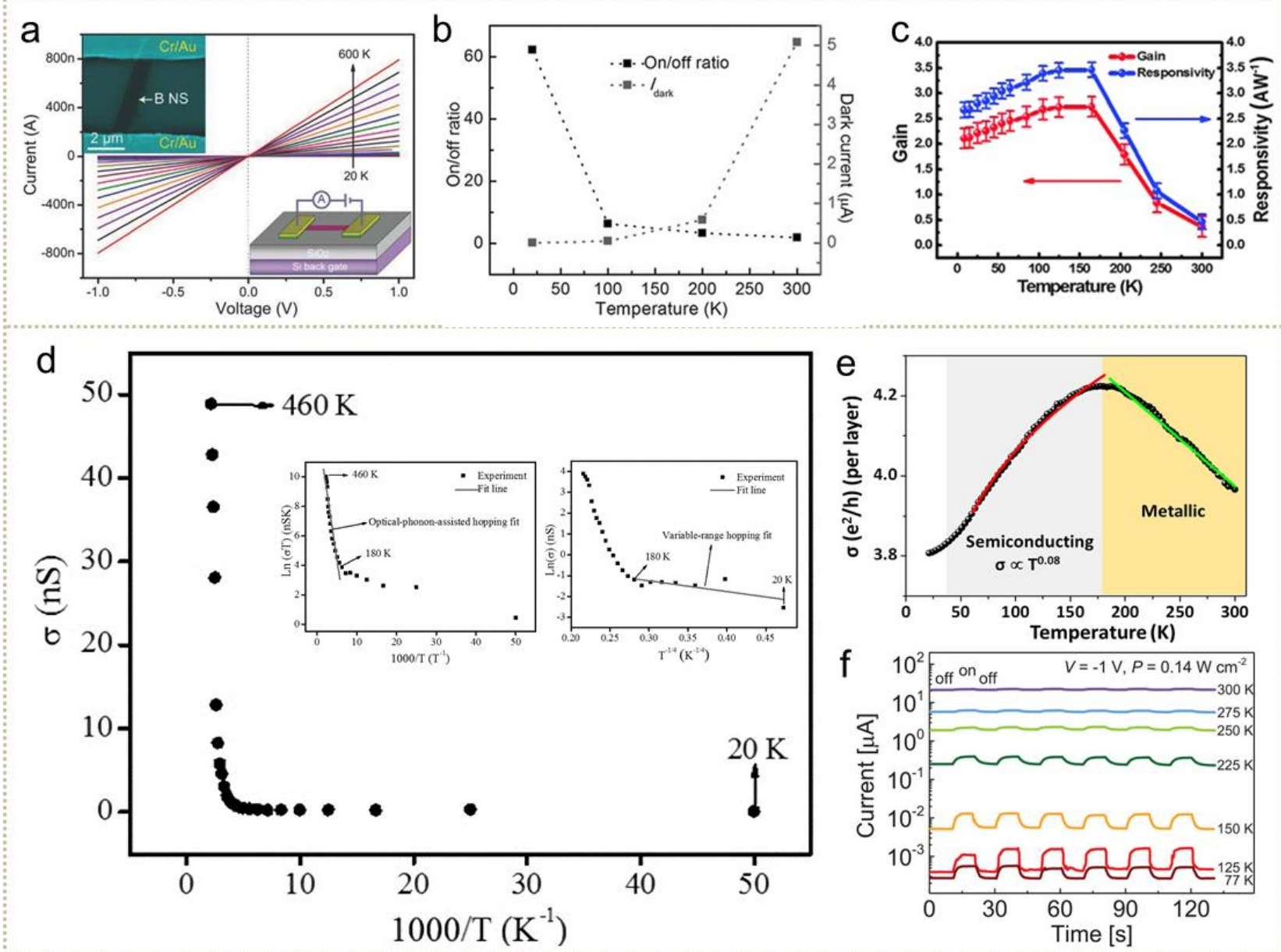

Figure 4. Cooling-enhanced phenomena on photoconductive photodetectors. (a) Temperature-dependent $J-V$ characteristics of ultrathin boron nanosheets (adapted from [87], with permission from Wiley-VCH, 2015). (b) Temperature-dependent on/off ratio and dark current in $\mathrm{Ta}_{2} \mathrm{NiSe}_{5}$ nanoflakes (adapted from [129], with permission from Wiley-VCH, 2016). (c) Temperature-dependent gain and responsivity in $\mathrm{Sb}_{2} \mathrm{Te}_{3}$ photodetectors (adapted from [128], with permission from the Royal Society of Chemistry, 2015). (d) Schematic of photoconductivity variation with temperature (adapted from [130], with permission from Wiley-VCH, 2017). (e) Photoconductivity of graphene (adapted from [74], with permission from the American Chemical Society, 2020). (f) Current variation under cycled light at different temperatures (adapted from [20], with permission from Wiley-VCH, 2017).

To comprehend the underlying mechanisms of temperature variation and photoconductive performance, temperature-dependent conductivity $(\sigma)$, which is dominated by the interaction between phonons and carriers or polarons, has been widely investigated. As show in Figure 4d as an example and guided by Mott's model [108], the plot of conductivity inverse temperature can be divided into two fitted near-linear curves representing nearest neighbor hopping $(\mathrm{M}-\mathrm{NNH})$ and the variable range hopping mechanism $(\mathrm{M}-\mathrm{VRH})$, respectively. For the $\mathrm{GeSe}_{2}$ photoconductor [130], the nearest neighbor hopping mechanism dominates conduction variation from 180 to $460 \mathrm{~K}$, and variable range hopping is fitted to conduction changes from 20 to $180 \mathrm{~K}$. In the nearest neighbor hopping region, the hopping of small polarons is assisted by optical phonons. The activation energy for the hopping conduction mechanism has been proposed by Austin and Mott [131,132], as follows:

$$
\begin{gathered}
W=W_{D}+\frac{1}{2} W_{H}, T>\frac{1}{2} \theta_{D} \\
W \cong W_{D}, T<\frac{1}{4} \theta_{D}
\end{gathered}
$$


where $\theta_{D}$ is Debye temperature, $W_{H}$ and $W_{D}$ represent hopping energy and disorder energy, respectively. As the temperature drops further, the optical phonons' energy becomes inadequate to maintain high conduction. Thus, the variable hopping mechanism, assisted by single acoustic phonons, is suitable for low temperature. There are a handful of experiments that evidenced this conduction-temperature model as accounting for temperature-dependent sensing performance, such as HgTe QDs [133], PbS/polystyrene nanocomposite [77], boron sheet [87], InI [134] and monolayer graphene [79]. What deserves notification are conduction changes raised by phase transition, which needs to be analyzed based on specific situations. In Figure 4e, Mogera et al. investigated the temperature-dependent conductivity of twisted multilayer graphene and observed peak conductivity appearing at $\sim 180 \mathrm{~K}$, indicating semiconducting to metallic transition [74].

Moreover, there are still challenges for photoconductive light sensors to overcome the huge dark current at room temperature. This issue can be effectively solved with the proper cooling method, such as, for example, $\mathrm{Fe}_{3}(\mathrm{THT})_{2}\left(\mathrm{NH}_{4}\right)_{3}$ MOF-based photodetectors (Figure 4f). The photoswitching response of their MOF devices at various temperatures possessed different on/off ratios, reaching a maximum at $125 \mathrm{~K}$ [129]. The response to light with long wavelengths and weak power intensity can appear and increase at cooling temperatures. Huang et al. reported the phenomenon that black-phosphorus-based photodetectors show a high responsivity of $7 \times 10^{6} \mathrm{~A} \mathrm{~W}^{-1}$ at $900 \mathrm{~nm}$ laser with an intensity of $5 \mathrm{~mW} \mathrm{~cm}^{-2}$ [78], exceeding the detection limit at room temperature. Another research on Ge QDs photodetectors observes an extraordinary and obvious photoresponse to near-IR light with only $10 \mathrm{nW}$ of light intensity [135]. The enhanced weak light response is likely due to the integrating function of suppressed noise current and enhanced absorption.

In addition to photoconductive devices' performance, low temperature enhances carriers' inherent movement, evaluated by lifetime, mobility and concentrations simultaneously. There are also investigations covering these specific carriers' characteristic changes under variations in temperature. According to the definition of gain, carrier lifetime can be reflected by the calculated gain. A relationship between effective mobility and the temperature extracted from Te-based FET is fitted with $\mu_{\mathrm{Eff}} \propto \mathrm{T}^{-1.03}$ [47], corresponding with the phonon-scattering model [136]. However, the positive influence of temperature on mobility is not infinite. Radisavljevic et al. systematically measured the charge transport properties of monolayer $\mathrm{MoS}_{2}$ devices. At temperatures above $200 \mathrm{~K}$, mobility follows $\mu \sim \mathrm{T}^{-1.4}$, indicating a typical phonon-scattering limited behavior. With further decreases in temperature, mobility shows pronounced dropping due to charged impurities scattering. In this structure, the impurity scattering has been screened by depositing the top-gate dielectric.

\subsubsection{Photovoltaic Photodetectors}

Different from the photoconductive type, the photovoltaic-type photodetector is based on the generation, diffusion and collection of photogenerated carriers, and performance is mainly determined by photogenerated charge pairs. A crucial factor affecting the movement of photogenerated carriers, temperature-dependent phenomena are widely applied in both improving photodetection performance and reducing dark current. As depicted in Figure 5a, photocurrent density in InSb photodetector increases by two orders of magnitude when cooling from $300 \mathrm{~K}$ to $100 \mathrm{~K}$ [137]. Significant enhancements in detectivity and the suppression of noise current through cooling $\mathrm{ZnCdSe} / \mathrm{ZnCdMgS}$ quantum well photodetectors have been observed in Figure $5 b$ [35], increasing about five orders of magnitudes. The same phenomenon exists in the $\mathrm{ZnCdSe} / \mathrm{ZnCdMgS}$ quantum cascade type [138]. Moreover, the cooling method can improve the light-electricity conversion efficiency, enabling the development of self-powered detectors. In Figure $5 c$, detectivity shows negative T-dependent and mobility-related behavior, owing to suppressed phonon scattering. A similar rule works on III-V group-based photodetectors. Wu et al. measured the quantum efficiency spectra of type-II InAs/InAsSb superlattice infrared photodetectors, which increased from $39 \%$ at $300 \mathrm{~K}$ to $47 \%$ at $150 \mathrm{~K}$ [126]. The temperature dependence 
of quantum efficiency mainly owes to the enhancement of the absorption coefficient and changes in resistance, while the recombination mechanism dominates the dark-current reduction. Moreover, these photoelectric performances show negative temperature dependence, indicating well-enhanced signals at temperatures lower than room temperature.
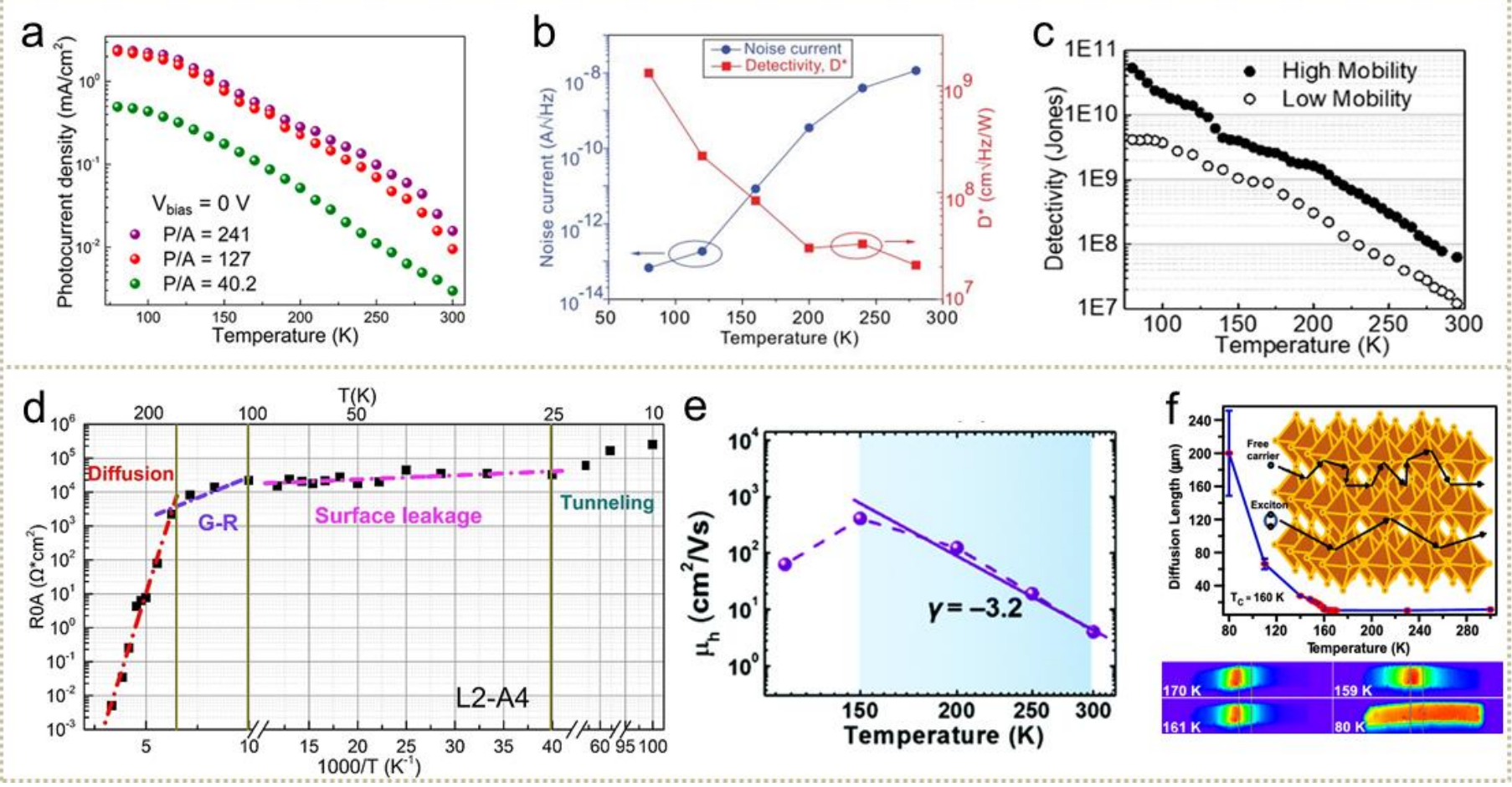

Figure 5. Cooling-enhanced phenomena on photovoltaic photodetectors. (a) The temperature-dependent photocurrent density of InSb photodetectors (adapted from [137], with permission from the American Chemical Society, 2018). (b) The low-temperature-enhanced detectivity and noise current of II-VI quantum well infrared photodetectors (adapted from [35], with permission from the American Institute of Physics, 2013). (c) The temperature-dependent detectivity of HgTe CDs photodetectors (adapted from [133], with permission from the American Chemical Society, 2019). (d) The temperature-dependent $\mathrm{R}_{0} \mathrm{~A}$ of InAs/GaSb photodetectors (adapted from [139], with permission from Elsevier, 2017). (e) Temperature-dependent $I-V$ characteristics and the corresponding mobility of perovskite photodetectors (adapted from [140], with permission from the Royal Society of Chemistry, 2018). (f) Temperature-dependent carriers' diffusion length of perovskite photodetectors (adapted from [37], with permission from the American Chemical Society, 2020).

One of the unique advantages of low-temperature cooling in photovoltaic photodetectors is the capability of inhibiting dark current in diodes. In prevalent infrared photodetectors, the dark current is derived from majority carrier drift, G-R, defects-related leakage, carrier diffusion and the tunnelling process [141-143]. Depicted in Figure 5d, the relationship between resistance area product $R_{0} A$, which represents dark current, and temperature experiences four stages in InAs/GaSb devices [139]. For these devices, the carrier diffusion process with activation energy becomes the main source of dark current from 300 to $160 \mathrm{~K}$, showing the greatest temperature dependence. At the 100 to $140 \mathrm{~K}$ temperature range, the dominant mechanism turns to the G-R mechanism, which is dominated by Shockley-Read-Hall (SRH) processes in the depletion region, where dark current drops fast with declining temperature. From 25 to $120 \mathrm{~K}$, small activation energy indicates that the defect-related leakage mainly contributes to dark current, which is less sensitive to temperature. If the temperature declines to near $10 \mathrm{~K}$, the tunneling process dominates and decreases dark current further. Similar research on InGaAs/GaAsSb also found decreasing trap density with lowering temperature, accounting for the suppressed dark current [144]. Except for the III-V group photodetectors [145], the effectivity of temperature-controlling 
dark current has also been verified by studies on other photovoltaic photodetectors, such as HgTe CQDs [53], InSb/Si [137], $\beta-\mathrm{FeSi}_{2} / \mathrm{Si}$ [146], HgCdTe [101] and so on.

Moreover, the cooling process can simultaneously enhance performance through regulating absorption and carriers' motion. For the temperature-dependent $J-V$ characteristics, the open circuit voltage, listed in Table 1, in an ideal p-n junction can be addressed with a more specific formula [53]:

$$
\text { Voc }=\frac{\mathrm{E}_{\mathrm{g}}}{\mathrm{e}}-\frac{\mathrm{k}_{\mathrm{b}} \mathrm{T}}{\mathrm{e}} \ln \left(\frac{\mathrm{N}_{\mathrm{c}} \mathrm{N}_{\mathrm{v}}}{\mathrm{np}}\right)
$$

where $N_{c}, N_{v}$ is the conduction band or valence band density of states and $n / p$ is the electron/hole concentration. The negative relationship between $V_{O C}$ and temperature is responsible for the increased efficiency at low temperature [21]. Jia et al. demonstrated the phenomenon of increasing photocurrent density with temperature decreasing in InSb photodetectors, ascribing it to longer carrier lifetime at lower temperatures [137]. A similar report on $\mathrm{CdS} / \mathrm{PbSe}$ demonstrated longer carrier diffusion length through a cooling process [19]. Likewise, photovoltaic photocurrent is reported to increase with temperature decreasing, as shown, for example, in Figure 5e. The negative T-coefficient of photocurrent in $\mathrm{MAPbI}_{3}$ diodes is likely due to hole mobilities [140]. Based on the T-behavior of mobility, both acoustic phonon scattering and MA polarization disorder are responsible for the activation of mobility. Another key parameter of carrier motion is diffusion length or charge lifetime, shown in Figure 5f. McClintock et al. reported a rapid increase in diffusion length when temperatures cool to $80 \mathrm{~K}$ and assumed increased exciton fraction as an inducement [37]. Investigation of $\mathrm{HgTe}$ QDs found the same negative temperature coefficient of mobility due to cooling reducing tunneling barriers within QDs [147]. In general, the cooling enhanced photocurrent is based on the integration of carriers' motion, carriers density and trap density.

Furthermore, cooling-enhanced photovoltaic devices with lateral photovoltaic effect (LPV) and bulk voltaic effect (BPV) are investigated. The position responsivity of ITO/Si has been researched by Qiao et al. showing $7.47 \mathrm{mV} / \mathrm{mm}$ at $80 \mathrm{~K}$. This is about 1.91 times of performance at $295 \mathrm{~K}$ [148], attributed to different Schottky barriers at various temperatures. Previous reports on the $\mathrm{BPV}$ effect in $\mathrm{PbZr}_{0.2} \mathrm{Ti}_{0.8} \mathrm{O}_{3}$ (PZT) have observed increasing $\mathrm{V}_{\mathrm{oc}}$ and decreasing dark current due to the temperature-influenced resistance of the Schottky barrier at ferroelectric-electrode interfaces [52].

\subsubsection{Photogating Photodetectors}

For 2D layered materials and their hybrid nanostructures, the photogating effect is a common mechanism that modulates structures' photoconductivity through photogenerated local electric fields. Different from the linear relationship of photocurrent and light intensity in photoconductive mode, the photogating sensor performs with a sublinear tendency due to the underlying long-lived trap states [58]. Temperature-dependent research on photogating photodetectors is relatively lacking. Recently, Pradhan et al. fabricated a TeNW/graphene structure evidencing the feasibility of cryogenic-operation-enhanced optoelectronic performance [80], shown in Figure 6a. The photoresponsivity, represented as $\gamma$ in Figure $6 \mathrm{~b}$, increases with temperature declining for the tested wavelengths, suggesting suppressed thermal fluctuation at low temperatures. To explain this phenomenon, authors also measured the variation of resistance with temperature in Figure 6c. Under the cooling condition, higher resistance is beneficial in reducing the leakage of photoinduced charges through source and drain electrodes. In consequence, cooling functions on the system's resistance then improves photogating performance. In addition to regulations on the composition and morphology of 2D photogating semiconductors, the cooling method is promising regarding finely regulating photoresponse in photogating devices. 

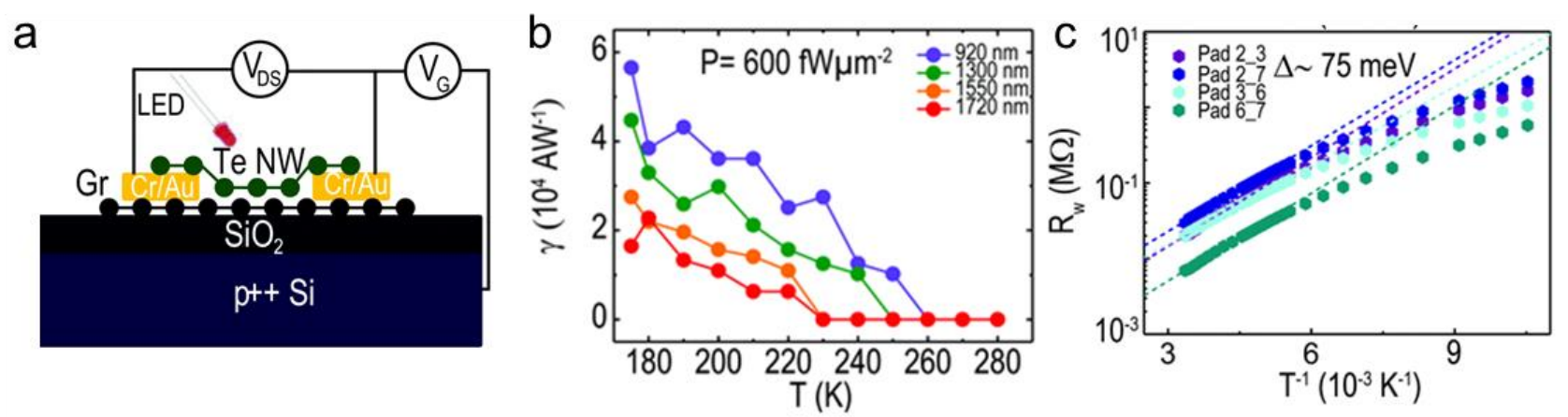

Figure 6. Cooling-enhanced phenomenon on photogating photodetectors. (a) The structure of photogating Te NW devices. (b) The temperature-dependent responsivity of Te NW devices. Reproduced with permission. (c) The temperature dependent-resistance of Te NW devices (adapted from [80], with permission from the Royal Society of Chemistry, 2017).

In conclusion, the cooling method is an effective way to enhance photodetection performance with impacts on absorption, photoconductivity, photogenerated carriers' movement and more. Herein, we summarize the reported low-temperature-enhanced photoresponse in Table 2. According to the discussion above, 2D materials and infrared photodetectors possessing fewer defects have potential for low-temperature enhancement, suggesting further application in space and polar regions.

Table 2. Summary of cooling-enhanced photodetection performance.

\begin{tabular}{|c|c|c|c|c|c|c|c|}
\hline \multirow{2}{*}{ Materials } & \multirow{2}{*}{ Type } & \multirow{2}{*}{ Wavelength } & \multicolumn{2}{|c|}{$300 \mathrm{~K}$} & \multicolumn{2}{|c|}{ Cryogenic } & \multirow{2}{*}{ Ref } \\
\hline & & & $\mathrm{R}(\mathrm{A} / \mathrm{W})$ & D (Jones) & $\mathrm{R}(\mathrm{A} / \mathrm{W})$ & D (Jones) & \\
\hline graphene-TeNW & PG & 920-1720 nm & 5 & $5 \times 10^{13}$ & $5.7 \times 10^{4}$ & & [80] \\
\hline $\mathrm{Te}$ & PC & $1-3.4 \mu \mathrm{m}$ & 16 & $2 \times 10^{9}$ & 27 & $2.6 \times 10^{11}$ & [47] \\
\hline Black-Phosphorus & PC & $400-900 \mathrm{~nm}$ & $\sim 10^{3}$ & & $7 \times 10^{6}$ & & [78] \\
\hline A-GNRs (a) & & & & $\sim 2.2 \times 10^{8}$ & & $\sim 2.1 \times 10^{11}$ & [81] \\
\hline HgTe QDs & PC & $3-5.25 \mu \mathrm{m}$ & $\sim 0.001$ & $\sim 10^{7}$ & $\sim 0.1$ & $\sim 5 \times 10^{10}$ & [149] \\
\hline $\mathrm{HgTe} / \mathrm{Ag}_{2} \mathrm{Te}$ CQDs & PV & $4-5 \mu \mathrm{m}$ & $\sim 0.1$ & $\sim 3 \times 10^{8}$ & 0.56 & $\sim 10^{11}$ & [53] \\
\hline HgTe CQDs & PV & $3-5 \mu \mathrm{m}$ & & $7.2 \times 10^{8}$ & 1.46 & $4 \times 10^{11}$ & [102] \\
\hline PbSe CQDs & PC & & & $\sim 1 \times 10^{13}$ & & $8.1 \times 10^{13}$ & [150] \\
\hline $\mathrm{Sb}_{2} \mathrm{Te}_{3}$ & PC & $\sim 980 \mathrm{~nm}$ & $\sim 0.5$ & & $\sim 3.5$ & & [128] \\
\hline Te-hyperdoped Si & PV & $3-5 \mu \mathrm{m}$ & & $\sim 10^{9}$ & & $\sim 10^{11}$ & [151] \\
\hline InAs $/ \operatorname{InAs}_{1-\mathrm{x}} \mathrm{Sb}_{\mathrm{x}}$ & PV & $\sim 4.75 \mu \mathrm{m}$ & 0.78 & $\sim 10^{9}$ & $\sim 0.7$ & $2.9 \times 10^{12}$ & [152] \\
\hline InAs/GaAs & PV & $2.5-7 \mu \mathrm{m}$ & $\sim 3$ & $2.4 \times 10^{8}$ & $\sim 27$ & $2 \times 10^{9}$ & [153] \\
\hline InAs/Si & PC & $1.4-3 \mu \mathrm{m}$ & & $1.4 \times 10^{5}$ & $60.4 \times 10^{-3}$ & $6 \times 10^{7}$ & [154] \\
\hline InAs/GaSb & PV & $\sim 7 \mu \mathrm{m}$ & $\sim 0.14$ & $8.9 \times 10^{8}$ & 0.167 & $3.0 \times 10^{11}$ & [155] \\
\hline InAs/InP & PV & $3-5 \mu \mathrm{m}$ & & $6 \times 10^{7}$ & 0.822 & $2.8 \times 10^{11}$ & [156] \\
\hline InAs/InAsSb & PV & $\sim 5.1 \mu \mathrm{m}$ & & $2.5 \times 10^{9}$ & & $7.1 \times 10^{11}$ & [126] \\
\hline $\mathrm{InAs} / \mathrm{AlAsSb}$ & PV & $4-5 \mu \mathrm{m}$ & $1.9 \times 10^{-3}$ & $2.7 \times 10^{7}$ & $\sim 6.8 \times 10^{-3}$ & $\sim 10^{9}$ & [63] \\
\hline InAsSb/InSb & PV & $\sim 4.6 \mu \mathrm{m}$ & & $\sim 5 \times 10^{9}$ & & $6 \times 10^{11}$ & [157] \\
\hline InAs/GaAs/InGaAs/InAlAs & PV & $3-5 \mu \mathrm{m}$ & $0.6 \times 10^{-3}$ & $4.83 \times 10^{6}$ & $1.21 \times 10^{-3}$ & $3.64 \times 10^{11}$ & [158] \\
\hline $\mathrm{Ge} / \mathrm{Ge}_{0.975} \mathrm{Sn}_{0.025} / \mathrm{Ge}$ & PV & $\sim 2 \mu \mathrm{m}$ & $\sim 0.1$ & & $\sim 0.3$ & & [14] \\
\hline $\mathrm{Ge}_{0.9} \mathrm{Sn}_{0.1} / \mathrm{Si}$ & PV & $\sim 2.4 \mu \mathrm{m}$ & 0.26 & & 2.85 & $4 \times 10^{9}$ & [159] \\
\hline $\mathrm{Bi}_{2} \mathrm{O}_{2} \mathrm{Se}$ & PC & UV-NIR & 6.5 & $8.3 \times 10^{11}$ & 1.7 & $\sim 1.3 \times 10^{12}$ & [160] \\
\hline $\mathrm{Ta}_{2} \mathrm{NiSe}_{5}$ & PC & & 17.21 & & 62.22 & & [129] \\
\hline $\mathrm{Pb}_{1-\mathrm{x}} \mathrm{Sn}_{\mathrm{x}} \mathrm{Se}$ & PC & $3-5 \mu \mathrm{m}$ & 0.21 & $1.1 \times 10^{12}$ & 0.19 & $7.7 \times 10^{13}$ & [51] \\
\hline $\mathrm{ZnCdSe} / \mathrm{ZnCdMgSe}$ & PV & $3-8 \mu \mathrm{m}$ & $\sim 0.2 \times 10^{-3}$ & $10^{5}$ & $40 \times 10^{-3}$ & $3.1 \times 10^{10}$ & [138] \\
\hline $\mathrm{Zn}_{0.51} \mathrm{Cd}_{0.4} \mathrm{Se} / \mathrm{Zn}_{0.29} \mathrm{Cd}_{0.26} \mathrm{Mg}_{0.45} \mathrm{Se}$ & PV & $3-5 \mu \mathrm{m}$ & 30 & $4 \times 10^{7}$ & & $2 \times 10^{9}$ & [35] \\
\hline $\mathrm{Fe}_{3}(\mathrm{THT})_{2}\left(\mathrm{NH}_{4}\right)_{3}$ & PC & $400-1575 \mathrm{~nm}$ & & $3 \times 10^{8}$ & & $7 \times 10^{8}$ & [20] \\
\hline
\end{tabular}

(a) A-GNRs: Armchair graphene nanoribbons. 


\subsection{Performance of Solar Cells}

The capability of converting solar energy to applicable electronic energy renders great attention to solar cells, especially for low-cost solution-processed types [161]. Thin-film solar cells, such as perovskite and CZTS, yield remarkable power conversion efficiencies (PCEs) while still being behind the predicted Shockley-Queisser (S-Q) limit [162]. Moreover, stability in severe environments puts forward strict requirements for the balance between application and performance. Low-temperature operation is expected to reach its aims based on the intrinsic photoelectric mechanism. Figure $7 \mathrm{a}$ shows that $\mathrm{V}_{O C}$ varies with the temperature of CZTS-type solar cells [57], owing to higher minority carriers' lifetime at low temperature. Taskensen et al. also witnessed the simultaneous improvement of $\mathrm{V}_{O C}$ and fill factor (FF) on CZTSe solar cells during cooling to $240 \mathrm{~K}$ [163]. As illustrated in Figure $7 \mathrm{~b}$, both the FF and PCE of hybrid perovskite solar cells significantly increase with declining temperature [164]. Temperature-dependent photovoltaic properties are closely related to light absorption, the motion of photogenerated carriers and even the structure and composition of devices.

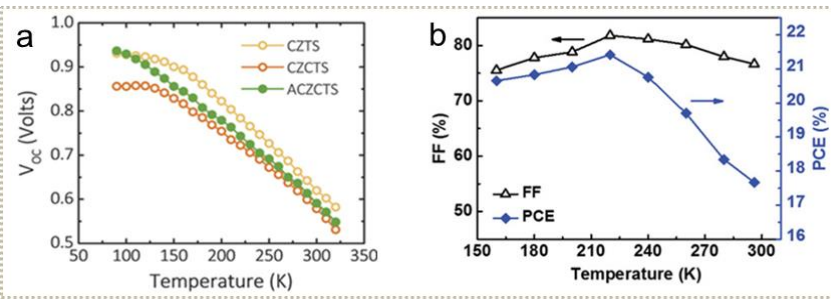

Factors Influencing Hybrid Perovskites at Low Temperature
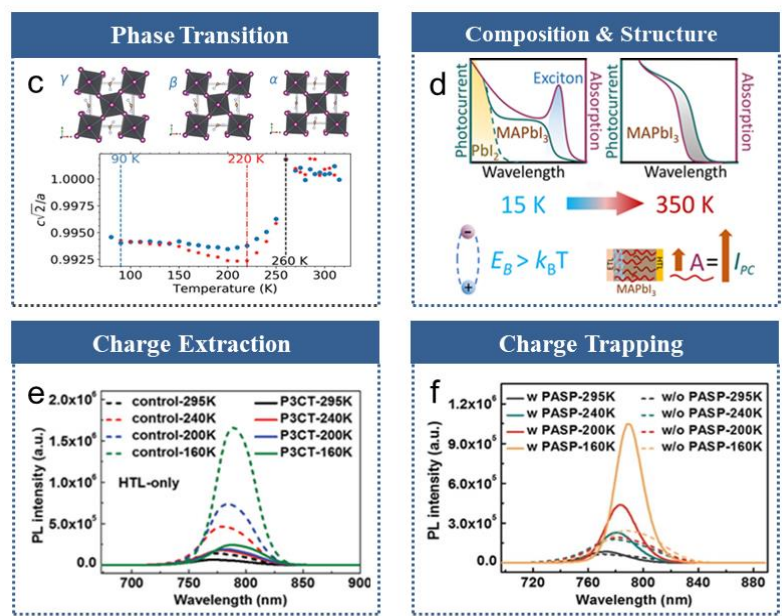

Charge Recombination

Poling \& Hysteresis
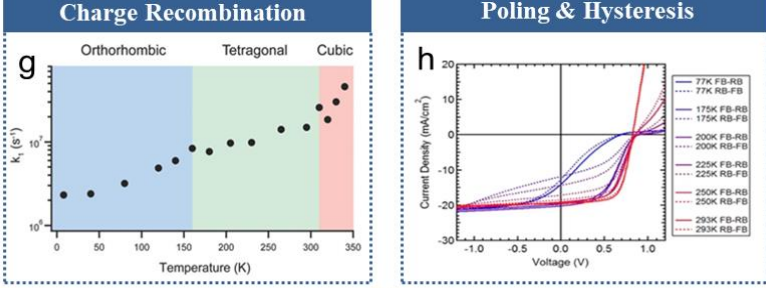

Figure 7. Low-temperature enhanced phenomena on solar cells. (a) Temperature-dependent $\mathrm{V}_{\mathrm{OC}}$ of CZTS-based solar cells (adapted from [57], with permission from Wiley-VCH, 2018). (b) Coolingenhanced PCE and FF of perovskite solar cells (adapted from [164], with permission from Wiley-VCH, 2019). (c) Phase transition (adapted from [39], with permission from Wiley-VCH, 2019). (d) Composition and structure (adapted from [165], with permission from Wiley-VCH, 2018). (e) Charge extraction. (f) Charge trapping (adapted from [164], with permission from Wiley-VCH, 2019). (g) Recombination rate (adapted from [30], with permission from Wiley-VCH, 2015). (h) Poling and hysteresis (adapted from [166], with permission from the American Chemical Society, 2015). 
Among thin-film solar cells, organic-inorganic hybrid perovskite solar cells have been reported to have advantages in a superior absorption coefficient, less excitons banding energy and an optimal energy level [166]. The cooling method has been utilized to explore the photoelectric process of perovskite materials and enhance their photoelectric output. To demonstrate the working mechanism of cooling, we summarize the most representative factors influencing hybrid perovskite solar cells' performance at low temperature in Figure $7 \mathrm{c}-\mathrm{h}$. As mentioned before, both the PL maximum and absorption onset wavelength of organic-inorganic hybrid perovskite solar cells show a discontinuous behavior, suggesting the existence of phase transition. For the methyammonium halide perovskite type, as early as 1987, Poglitsch et al. observed the phase transition behaviour of $\mathrm{MAPbCl}_{3}, \mathrm{MAPbBr}_{3}$ and $\mathrm{MAPbI}_{3}$ from a cubic to an orthorhombic crystal structure [167], referred to as from $\alpha$-phase to $\beta$-phase and finally $\gamma$-phase, through lattice data when temperature decreases. There are also investigations focusing on the dynamic theory of phase transition [168-170], not discussed in detail here. In response to in-depth knowledge of the interplay between low-temperature-caused structure transition and optoelectronic properties, Greenland et al. verified the dominated phase of mixed-cation mixed-halide perovskite $\left(\mathrm{FAPbI}_{3}\right)_{0.85}\left(\mathrm{MAPbBr}_{3}\right)_{0.1}$ at different temperatures and observed sudden changes in absorption [39] and carrier density, as well as the recombination rate at the corresponding phase-transition temperature, shown in Figure 7c. Lou et al. reported the temperature-dependent spectral response of $\mathrm{FAPb}\left(\mathrm{Br}_{0.4} \mathrm{I}_{0.6}\right)_{3}$. They also reported that $\beta$-phase, which possess fewer defects and a narrower band gap, appears at low temperature [171]. Moreover, accompanied by phase transition, an obvious change in the trend of temperature-dependent mobility has been observed at transition temperatures [172]. Landi et al. systematically studied the temperature dependence of recombination trap density and the fluctuating trap density of $\mathrm{MAPbI}_{3}$, showing less trap concentration at low temperatures and obvious turning points during the phase transition region [31]. Another study by Parrott et al. extracted the effective PL lifetime of $\mathrm{FASn}_{\mathrm{x}} \mathrm{Pb}_{1-\mathrm{x}} \mathrm{I}_{3}$, with $\mathrm{x}=0.25$ and 1 , which increased with temperature reductions at each crystal-structure region, based on temperature-regulated recombination mechanisms [118]. Nevertheless, this experiment revealed that lead-rich $(x<0.5)$ perovskite possesses higher lifetime and increased stability compared with tin-rich $(x>0.5)$ perovskite, which is disturbed by natural defects. In addition to composition, pseudohalide additives are reported to enhance performance at low temperature by suppressing halide segregation [173]. Milot et al. further increased the effective charge-carrier mobility of $\mathrm{FASnI}_{3}$ at low temperature through the addition of $\mathrm{SnF}_{2}$, since hole-doping reduced recombination [36]. As Figure 7d illustrated, low-temperature enhancement testing of $\mathrm{MAPbI}_{3}$ showed remnant $\mathrm{PbI}_{2}$ contributing to higher photocurrent, especially at low temperatures [165]. Similar to enhancing methods at room temperature, charge-selective extraction plays an important role in enhancing cooling performance. Chen et al. studied cooling-caused variations in $\mathrm{MAPbBr}_{3}$ solar cells and proposed the insulating nature of a charge-extraction layer, rather than an absorption layer restricting performance at low temperature [174]. Represented by Figure 7e, the PL intensity of the charge-transporting layer is lowered compared to control samples at various temperatures, implying a more efficient charge transfer in interfaces, especially at low temperature [164]. Nevertheless, Shao et al. observed that deteriorated charge-carrier extraction caused a PCE drop at low temperature when using [60] PCBM as an electron extraction layer [103]. Subsequent experiments using a composite layer with higher electron extraction capability successfully raised PCE from $15.48 \%$ at $300 \mathrm{~K}$ to $17.72 \%$ at $215 \mathrm{~K}$ and $15.82 \%$ at $160 \mathrm{~K}$. Furthermore, charge-extraction layers, like planar or mesoporous, shows different cryogenic-enhanced behaviours [175]. The fourth factor is trap states in perovskite solar cells. Piana et al. proposed that trap states influenced the trapping and re-excitation of free carriers and excitons and found the trap-states' density maximum appearing at the tetragonal-orthorhombic phase transition temperature in $\mathrm{MAPbI}_{3-\mathrm{x}} \mathrm{Cl}_{\mathrm{x}}$ [38]. The rates of trapping declined from $\sim 10^{-8} \mathrm{~cm}^{3} \mathrm{~s}^{-1}$ at room temperature to $\sim 10^{-9} \mathrm{~cm}^{3} \mathrm{~s}^{-1}$ at low temperature due to less phonon-mediated recombination. Another experiment by Zhou et al. 
claimed the impact of surface passivation by PASP benefiting the reduction of trap states during temperature-dependent measurements [164]. The temperature dependence of charge-carrier recombination opens up a new mechanism for improving perovskite solar cells' output. As mentioned in Table 1, monomolecular recombination $\left(k_{1}\right)$, biomolecular recombination $\left(k_{2}\right)$ and Auger recombination $\left(k_{3}\right)$ dominate the recombination mechanisms of perovskite solar cells. Depicted in Figure $7 \mathrm{~g}, k_{1}$ decreased from $4.6 \times 10^{7} \mathrm{~s}^{-1}$ at $340 \mathrm{~K}$ to $2.3 \times 10^{6} \mathrm{~s}^{-1}$ at near $10 \mathrm{~K}$ in $\mathrm{MAPbI}_{3}$ devices. Since the low temperature passivates and freezes the dopant site, perovskite materials weakened by defects have promise of significant improvement at lower temperature. Different from $k_{1}, k_{2}$, which was evaluated with the Langevin model [176], generally exhibited a positive relationship with charge-carrier mobility, showing a low-temperature deteriorated trend. Recently, Davis et al. utilized the van Roosbroeck-Shockley relation to study the bimolecular recombination constant and found screening of the interactions between the electron-hole above the Mott transition to have potential in reducing $k_{2}$, providing a feasible way to improve biomolecular recombination-restricted performance at low temperature [17]. Investigations on $k_{3}$ reveals it is strongly dependent on carrier density [109] and monotonically increases as temperature declines [177]. The fluctuation of recombination composition brings pros and cons for cooling enhancement, which deserves in-depth research to reduce the overall recombination rate. Another breakthrough due to low-temperature operation is the hysteresis phenomenon. The hysteresis effect, originating from surface trap states, ferroelectricity and ion motion under applied bias [170,178-180], can be alleviated by freezing and bias poling. This is expected to promote the commercialization of perovskite solar cells. In temperature-dependent $J-V$ scans, plotted in Figure 7h, Bryant et al. addressed the low-temperature-retarding relaxation process in hysteresis effects for $0.6 \mathrm{~s}$ at room temperature to $15.5 \mathrm{~s}$ at $175 \mathrm{~K}$ [166]. The influence of cooling on the hysteresis loop is based on competition between ions frozen by lowering temperature and the thermal-activated ion transporting, trapping and detrapping process [181]. Zou et al. combined bias poling and temperature-dependent hysteresis by applying positive bias and cooling to freeze the perovskite to a steady poled state [55], which increased the fill factor from $\sim 0.3$ at room temperature to $\sim 0.7$ at $160 \mathrm{~K}$.

In general, low-temperature operation for solar cells is a rare but effective attempt. This method is connected with temperature-dependent changes in morphology, structure and overall carrier-charge motion. Development of cooling method can improve lightelectricity conversion efficiency and application in extremely cool circumstances.

\section{Applications of the Low-Temperature-Enhanced Photoelectric Process}

Advances in cooling-enhanced photoelectronic processes bring new opportunities to conventional photoelectrical nanomaterials, based on superiority in tuneable band alignment, suppressed noise current, a different mechanism of charge motion and so on, hence, enabling more innovative optoelectronic applications. The cooling method has been widely used in the photodetection field, especially for background-limited infrared photodetectors. As shown in Figure $8\left(\mathrm{a}_{1}\right)$, summarised by Wang et al., typical high-resolution photodetectors in the infrared field are dominated by materials with low-temperature operating requirements [143]. In addition to reduced dark current at cryogenic temperatures, significant enhanced detectivity makes the cooling method a more effective strategy for realizing highly sensitive photodetection. As shown, for example, by Figure $8\left(a_{2}, a_{3}\right)$, the III-V group photodetector acquires accuracy to distinguish details such as vessels when the temperature further drops to $60 \mathrm{~K}$ [66]. Despite difficulties in operation at extremely low temperature, the negative relationship between the temperature and the photoresponse of the discussed materials provides feasibility in greatly increasing devices' performance using the proper cooling process. In contrast to the mature application of cooling in photodetection, solar cells possessing complex configuration and integrated optoelectrical mechanisms are in the beginning stage. Recently, Chen et al. successfully fabricated an unencapsulated perovskite device exhibiting higher performance in a simulated near-space 
(especially low-temperature) environment [181]. The enhancement at low temperature mainly originates from the self-elimination of intrinsic defects brought by phase transition under a cooling environment. As illustrated in Figure $8 b$, when temperatures decrease from $300 \mathrm{~K}$ to $220 \mathrm{~K}$, the phase transition from cubic to tetragonal structure eliminates these intrinsic point defects then causes PCE to increase to $25.2 \%$ at $220 \mathrm{~K}$. Previous discussion also lists the utilization of the frozen hysteresis effect at suitable temperature to improve the conversion efficiency of perovskite solar cells. Further investigations are expected to demonstrate the enormous advantages of cooling-enhanced solar cells, especially perovskite in space, near polar regions and other cool conditions. Integrated optoelectronic effects with other sensing functions play an important role in next-generation communication, healthcare, bioelectronics and so on [23,182-193]. In 2020, Chang et al. investigated the low-temperature cooling-enhanced pryo-phototronic effect on SnS/CdS photodetectors, depicted in Figure $8\left(c_{1}, c_{2}\right)$. For this planar structure photodetector, significant enhancement $(\sim 500 \%)$ of the ratio of pyroelectric to total signal was achieved as temperature declined to $77 \mathrm{~K}$ [194]. Further research on $\mathrm{ZnO} /$ perovskite [195] and p-Si/n-ZnO [196] verified that low temperature improved the coupling effect phenomenon. The coupling mechanism was unveiled by $\mathrm{Ma}$ et al. with experiments on $\mathrm{BaTiO}_{3}$ [197], shown in Figure $8\left(\mathrm{c}_{3}, \mathrm{c}_{4}\right)$. Under low-temperature operation, shallow trap levels play a more important role in photoinduced response. At room temperature, the function of shallow traps has been suppressed. However, the temperature dependence of piezo-photoelectric effect showed that cooling weakens piezoelectric and photoelectric performance [198,199]; these results remain a puzzle in the investigation of photoelectricity-evolved coupling mechanisms at low temperature. More multifunctional detectors operating at low temperature deserve investigation, especially those based on low-temperature-enhancing mechanisms. Another challenge for cooling operations is the limit of difficulties in realizing extremely low temperatures. According to specific temperature-dependent effects of optoelectronic devices, it is recommended to lock in optimal performance by cooling to the proper temperature rather than extreme low temperature. For the negative temperature-dependent section, even slightly cooler temperature will cause invisible improvement. In this regard, we believe that investigations on cooling-enhanced performance will make breakthroughs in lowtemperature photoelectric application and push forward research on temperature-regulated optoelectrical mechanisms. 

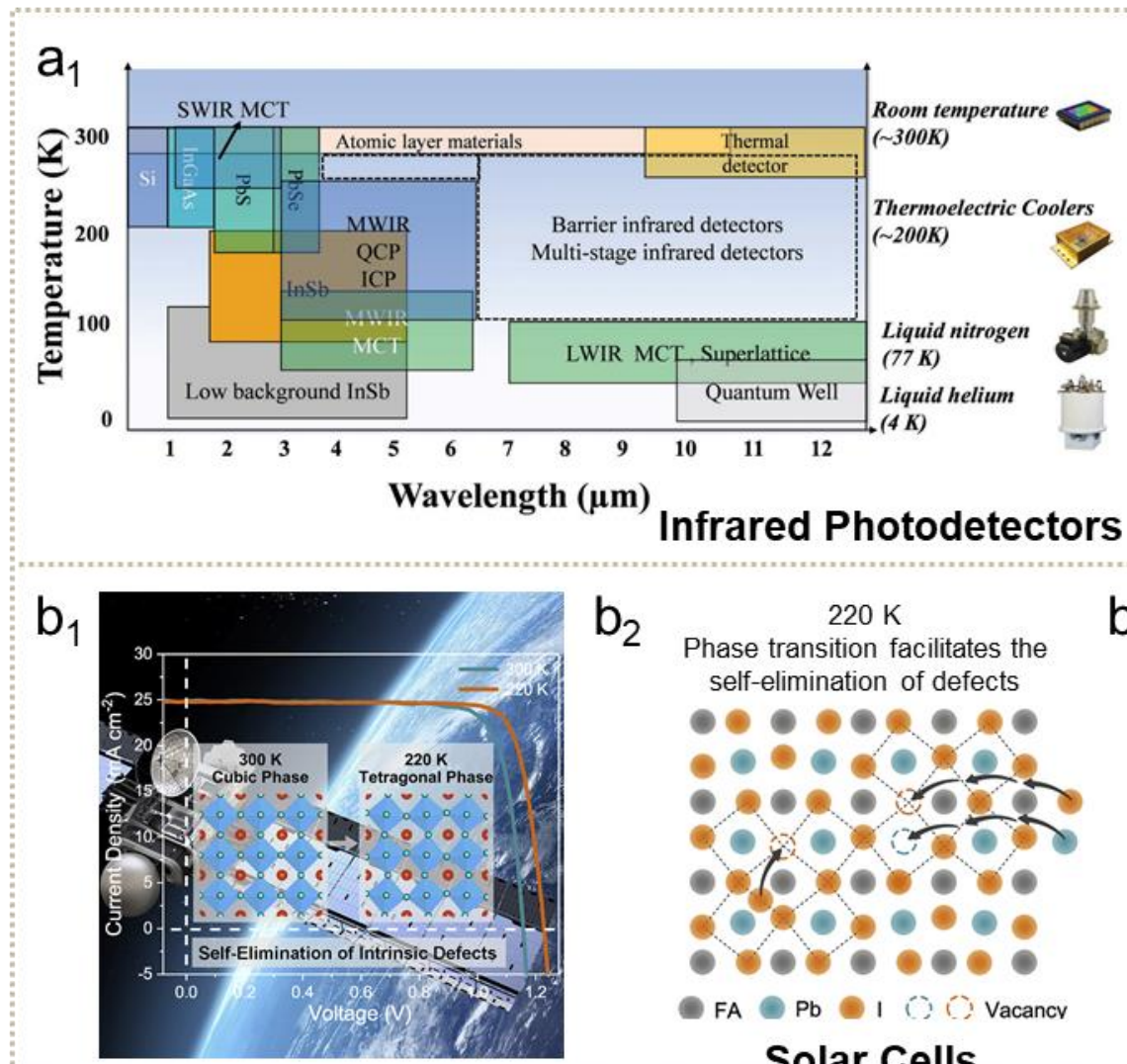

$a_{2}$

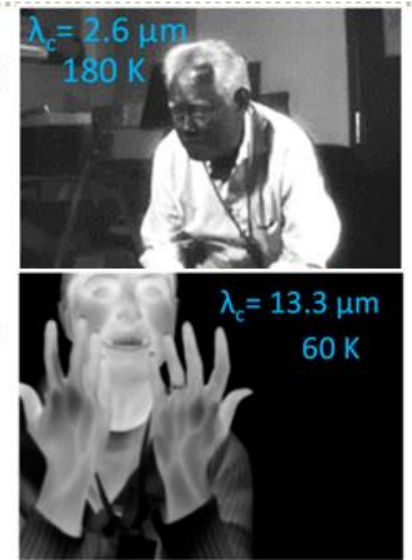

$300 \mathrm{~K}$

$b_{3}$

Phase transition facilitates the self-elimination of defects

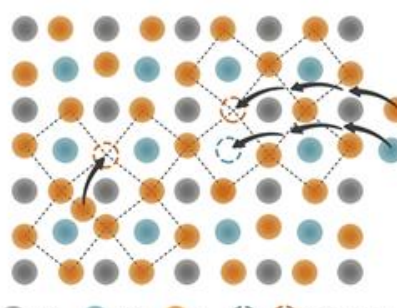

Top right, Schottky defects; Bottom left, Frenkel defects

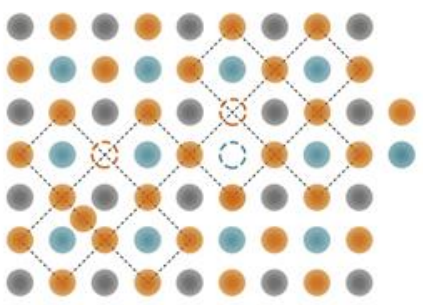

\section{Solar Cells}

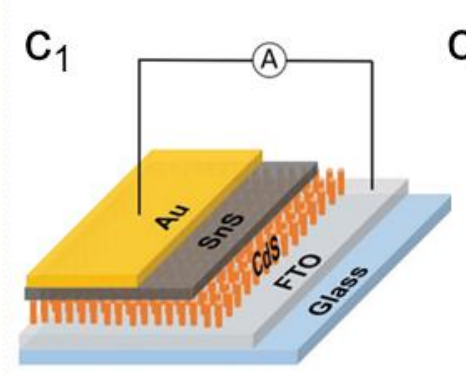

$\mathrm{C}_{2}$

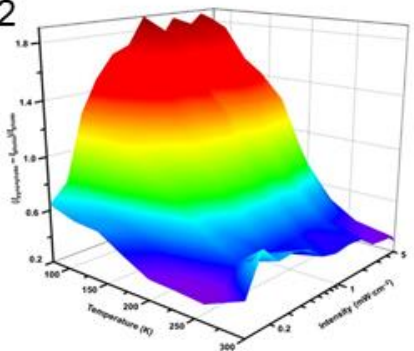

$\mathrm{C}_{3}$

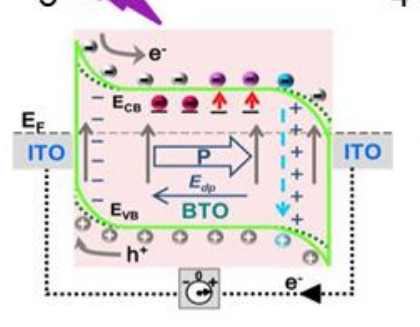

$\mathrm{C}_{4}$

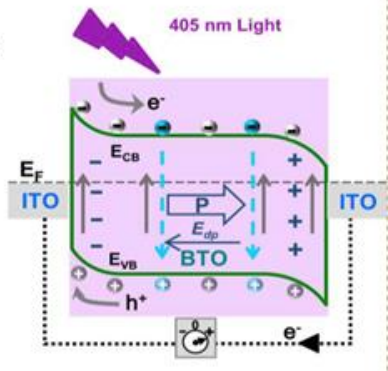

Multifunctional Sensors

Figure 8. Applications of the low-temperature cooling method for photoelectric devices. (a) Cooling application in infrared photodetectors. ( $\left.\mathbf{a}_{\mathbf{1}}\right)$ Summary of working temperature for infrared photodetectors (adapted from [143], with permission from Wiley-VCH, 2019). ( $\left.\mathbf{a}_{2}, \mathbf{a}_{3}\right)$ Temperature-dependent sensing performance of infrared photodetectors (adapted from [66], with permission from the Multidisciplinary Digital Publishing Institute, 2020). (b) Cooling application in solar cells (adapted from [181], with permission from Elsevier, 2020). (c) Cooling application in multifunction sensors. $\left(\mathbf{c}_{1}, \mathbf{c}_{2}\right)$ Cooling-enhanced pyro-photoelectric coupling effect (adapted from [194], with permission from Wiley-VCH, 2020). ( $\mathbf{c}_{3}, \mathbf{c}_{4}$ ) The underlying cooling-enhanced mechanism of the coupling effect (adapted from [197], with permission from Elsevier, 2019).

\section{Summary and Outlook}

In this review, we propose a low-temperature operation method with huge potential in photodetectors and solar cells without altering nanostructures or configurations and summarize the relevant advances of cooling methods in improving optoelectrical performance. Advances on cooling-enhanced photoelectric performance have proven its benefits to various materials and structures, for example, 2D photoconductors, III-Vs group infrared photodetectors and perovskite solar cells. In addition to the summary of cooling-enhanced photoelectric performance, in-depth mechanisms have been discussed in terms of different application types, represented by photodetectors and solar cells. Through analysis from materials to performance, the cooling method is based on the integration of bandgap 
optimization, recombination suppression, phase transition and so on. Moreover, there is also plenty of room to further improve photoelectric performance and realize practical applications of properly lowering temperature. Overall, the low-temperature cooling method, which lacked attention in recent decades, is capable of pushing forward photoelectric applications in harsh environments and featuring highly improved optoelectronic performance without complex modification.

Author Contributions: Conceptualization, L.W., Y.J., B.O., Z.L. and Y.Y.; methodology, L.W., Y.Y; resources, L.W.; writing—original draft preparation, L.W.; writing-review and editing, L.W., Y.J. and B.O.; supervision, Z.L., Y.Y.; project administration, Z.L., Y.Y.; funding acquisition, Y.Y. All authors have read and agreed to the published version of the manuscript.

Funding: This work was supported by the National Key R\&D Program of China (Grant No. 2016YFA0202701), the National Natural Science Foundation of China (Grant No. 52072041,), the University of Chinese Academy of Sciences (Grant No. Y8540XX2D2), the Qingdao National Laboratory for Marine Science and Technology (No. 2017ASKJ01).

Data Availability Statement: No new data were created or analyzed in this study. Data sharing is not applicable to this article.

Conflicts of Interest: The authors declare no conflict of interest.

\section{References}

1. Jung, H.S.; Park, N.G. Perovskite solar cells: From materials to devices. Small 2015, 11, 10-25. [CrossRef] [PubMed]

2. Tian, W.; Liu, D.; Cao, F.; Li, L. Hybrid Nanostructures for Photodetectors. Adv. Opt. Mater. 2016, 5, 4. [CrossRef]

3. Koppens, F.H.L.; Mueller, T.; Avouris, P.; Ferrari, A.C.; Vitiello, M.S.; Polini, M. Photodetectors based on graphene, other two-dimensional materials and hybrid systems. Nat. Nanotechnol. 2014, 9, 780-793. [CrossRef]

4. Nasiri, N.; Jin, D.; Tricoli, A. Nanoarchitechtonics of Visible-Blind Ultraviolet Photodetector Materials: Critical Features and Nano-Microfabrication. Adv. Opt. Mater. 2019, 7, 2. [CrossRef]

5. Guo, W.; Yang, Y.; Qi, J.; Zhao, J.; Zhang, Y. Localized ultraviolet photoresponse in single bent ZnO micro/nanowires. Appl. Phys. Lett. 2010, 97, 133112. [CrossRef]

6. Yang, Y.; Zhang, H.; Lin, Z.-H.; Liu, Y.; Chen, J.; Lin, Z.; Zhou, Y.S.; Wong, C.P.; Wang, Z.L. A hybrid energy cell for self-powered water splitting. Energy Environ. Sci. 2013, 6, 2429-2434. [CrossRef]

7. Ouyang, B.; Zhang, K.; Yang, Y. Self-Powered UV Photodetector Array Based on P3HT/ZnO Nanowire Array Hetero-junction. Adv. Mater. Technol. 2017, 2, 1700208. [CrossRef]

8. Ouyang, B.; Zhang, K.; Yang, Y. Photocurrent Polarity Controlled by Light Wavelength in Self-Powered ZnO Nanowires/SnS Photodetector System. iScience 2018, 1, 16-23. [CrossRef]

9. Qi, J.; Ma, N.; Ma, X.; Adelung, R.; Yang, Y. Enhanced Photocurrent in $\mathrm{BiFeO}_{3}$ Materials by Coupling Temperature and ThermoPhototronic Effects for Self-Powered Ultraviolet Photodetector System. ACS Appl. Mater. Interfaces 2018, 10, 13712-13719. [CrossRef]

10. Glavin, N.R.; Rao, R.; Varshney, V.; Bianco, E.; Apte, A.; Roy, A.; Ringe, E.; Ajayan, P.M. Emerging Applications of Elemental 2D Materials. Adv. Mater. 2020, 32, e1904302. [CrossRef]

11. Lan, C.; Shi, Z.; Cao, R.; Li, C.; Zhang, H. 2D materials beyond graphene toward Si integrated infrared optoelectronic devices. Nanoscale 2020, 12, 11784-11807. [CrossRef]

12. Wu, J.; Lu, Y.; Feng, S.; Wu, Z.; Lin, S.; Hao, Z.; Yao, T.; Li, X.; Zhu, H.; Lin, S. The Interaction between Quantum Dots and Graphene: The Applications in Graphene-Based Solar Cells and Photodetectors. Adv. Funct. Mater. 2018, 28, 50. [CrossRef]

13. Cojocaru, L.; Uchida, S.; Sanehira, Y.; Gonzalez-Pedro, V.; Bisquert, J.; Nakazaki, J.; Kubo, T.; Segawa, H. Temperature Effects on the Photovoltaic Performance of Planar Structure Perovskite Solar Cells. Chem. Lett. 2015, 44, 1557-1559. [CrossRef]

14. Chang, C.; Li, H.; Huang, S.H.; Cheng, H.H.; Sun, G.; Soref, R.A. Sn-based Ge/Ge0.975Sn0.025/Ge p-i-n photodetector operated with back-side illumination. Appl. Phys. Lett. 2016, 108, 151101. [CrossRef]

15. Cao, R.; Xu, F.; Zhu, J.; Ge, S.; Wang, W.; Xu, H.; Xu, R.; Wu, Y.; Ma, Z.; Hong, F.; et al. Unveiling the Low-Temperature Pseudodegradation of Photovoltaic Performance in Planar Perovskite Solar Cell by Optoelectronic Observation. Adv. Energy Mater. 2016, 6, 18. [CrossRef]

16. Zhang, H.; Qiao, X.; Shen, Y.; Moehl, T.; Zakeeruddin, S.M.; Grätzel, M.; Wang, M. Photovoltaic behaviour of lead methylammonium triiodide perovskite solar cells down to 80 K. J. Mater. Chem. A 2015, 3, 11762-11767. [CrossRef]

17. Davies, C.L.; Filip, M.R.; Patel, J.B.; Crothers, T.W.; Verdi, C.; Wright, A.D.; Milot, R.L.; Giustino, F.; Johnston, M.B.; Herz, L.M. Bimolecular recombination in methylammonium lead triiodide perovskite is an inverse absorption process. Nat. Commun. 2018, 9, 1-9. [CrossRef] [PubMed]

18. Woo, H.C.; Choi, J.W.; Shin, J.; Chin, S.-H.; Ann, M.H.; Lee, C.-L. Temperature-Dependent Photoluminescence of CH3NH3PbBr3 Perovskite Quantum Dots and Bulk Counterparts. J. Phys. Chem. Lett. 2018, 9, 4066-4074. [CrossRef] [PubMed] 
19. Weng, B.; Qiu, J.; Zhao, L.; Chang, C.; Shi, Z. CdS/PbSe heterojunction for high temperature mid-infrared photovoltaic detector applications. Appl. Phys. Lett. 2014, 104, 121111. [CrossRef]

20. Arora, H.; Dong, R.; Venanzi, T.; Zscharschuch, J.; Schneider, H.; Helm, M.; Feng, X.; Cánovas, E.; Erbe, A. Demonstration of a Broadband Photodetector Based on a Two-Dimensional Metal-Organic Framework. Adv. Mater. 2020, 32, e1907063. [CrossRef] [PubMed]

21. Wei, W.; Bao, X.-Y.; Soci, C.; Ding, Y.; Wang, Z.-L.; Wang, D. Direct Heteroepitaxy of Vertical InAs Nanowires on Si Substrates for Broad Band Photovoltaics and Photodetection. Nano Lett. 2009, 9, 2926-2934. [CrossRef] [PubMed]

22. Wang, Y.; Zhu, L.; Feng, Y.; Wang, Z.; Wang, Z.L. Comprehensive Pyro-Phototronic Effect Enhanced Ultraviolet Detector with $\mathrm{ZnO} / \mathrm{Ag}$ Schottky Junction. Adv. Funct. Mater. 2018, 29. [CrossRef]

23. Ma, N.; Zhang, K.; Yang, Y. Photovoltaic-Pyroelectric Coupled Effect Induced Electricity for Self-Powered Photodetector System. Adv. Mater. 2017, 29, 46. [CrossRef] [PubMed]

24. Zhang, Y.; Zhai, J.; Wang, Z.L. Piezo-Phototronic Matrix via a Nanowire Array. Small 2017, 13, 1702377. [CrossRef] [PubMed]

25. Liu, Y.; Yang, Q.; Zhang, Y.; Yang, Z.; Wang, Z.L. Nanowire Piezo-phototronic Photodetector: Theory and Experimental Design. Adv. Mater. 2012, 24, 1410-1417. [CrossRef]

26. Datta, S.; Gokhale, M.R.; Shah, A.P.; Arora, B.M.; Kumar, S. Temperature dependence of surface photovoltage of bulk semiconductors and the effect of surface passivation. Appl. Phys. Lett. 2000, 77, 4383-4385. [CrossRef]

27. Soibel, A.; Keo, S.A.; Fisher, A.; Hill, C.J.; Luong, E.; Ting, D.Z.; Gunapala, S.D.; Lubyshev, D.; Qiu, Y.; Fastenau, J.M.; et al. High operating temperature nBn detector with monolithically integrated microlens. Appl. Phys. Lett. 2018, 112, 041105. [CrossRef]

28. Villegas, C.E.P.; Rocha, A.R.; Marini, A. Anomalous Temperature Dependence of the Band Gap in Black Phosphorus. Nano Lett. 2016, 16, 5095-5101. [CrossRef] [PubMed]

29. Soibel, A.; Hill, C.J.; Keo, S.A.; Höglund, L.; Rosenberg, R.; Kowalczyk, R.; Khoshakhlagh, A.; Fisher, A.; Ting, D.Z.-Y.; Gunapala, S.D. Room temperature performance of mid-wavelength infrared InAsSb nBn detectors. Appl. Phys. Lett. 2014, 105, 023512. [CrossRef]

30. Milot, R.L.; Eperon, G.E.; Snaith, H.J.; Johnston, M.B.; Herz, L.M. Temperature-Dependent Charge-Carrier Dynamics in CH3NH3PbI3 Perovskite Thin Films. Adv. Funct. Mater. 2015, 25, 6218-6227. [CrossRef]

31. Landi, G.; Neitzert, H.C.; Barone, C.; Mauro, C.; Lang, F.; Albrecht, S.; Rech, B.; Pagano, S. Correlation between Elec-tronic Defect States Distribution and Device Performance of Perovskite Solar Cells. Adv. Sci. 2017, 4, 1700183. [CrossRef]

32. Yang, B.; Ming, W.; Du, M.H.; Keum, J.K.; Puretzky, A.A.; Rouleau, C.M.; Huang, J.; Geohegan, D.B.; Wang, X.; Xiao, K. Real-Time Observation of Order-Disorder Transformation of Organic Cations Induced Phase Transition and Anomalous Photoluminescence in Hybrid Perovskites. Adv. Mater. 2018, 30, e1705801. [CrossRef]

33. Grotevent, M.J.; Hail, C.U.; Yakunin, S.; Bachmann, D.; Kara, G.; Dirin, D.N.; Calame, M.; Poulikakos, D.; Kovalenko, M.V.; Shorubalko, I. Temperature-Dependent Charge Carrier Transfer in Colloidal Quantum Dot/Graphene Infrared Photodetectors. ACS Appl. Mater. Interfaces 2020, 13, 848-856. [CrossRef]

34. Dar, M.I.; Jacopin, G.; Meloni, S.; Mattoni, A.; Arora, N.; Boziki, A.; Zakeeruddin, S.M.; Rothlisberger, U.; Grätzel, M. Origin of unusual bandgap shift and dual emission in organic-inorganic lead halide perovskites. Sci. Adv. 2016, 2, e1601156. [CrossRef]

35. Ravikumar, A.P.; Chen, G.; Zhao, K.; Tian, Y.; Prucnal, P.R.; Tamargo, M.C.; Gmachl, C.F.; Shen, A. Room Temperature and High Responsivity Short Wavelength II-VI Quantum Well Infrared Photodetector. Appl. Phys. Lett. 2013, 102, CTh4J.3. [CrossRef]

36. Milot, R.L.; Klug, M.T.; Davies, C.L.; Wang, Z.; Kraus, H.; Snaith, H.J.; Johnston, M.B.; Herz, L.M. The Effects of Doping Density and Temperature on the Optoelectronic Properties of Formamidinium Tin Triiodide Thin Films. Adv. Mater. 2018, 30, e1804506. [CrossRef]

37. McClintock, L.; Xiao, R.; Hou, Y.; Gibson, C.; Travaglini, H.C.; Abramovitch, D.; Tan, L.Z.; Senger, R.T.; Fu, Y.; Jin, S.; et al. Temperature and Gate Dependence of Carrier Diffusion in Single Crystal Methylammonium Lead Iodide Perovskite Microstructures. J. Phys. Chem. Lett. 2020, 11, 1000-1006. [CrossRef] [PubMed]

38. Piana, G.M.; Bailey, C.G.; Lagoudakis, P.G. Phonon-Assisted Trapping and Re-excitation of Free Carriers and Excitons in Lead Halide Perovskites. J. Phys. Chem. C 2019, 123, 19429-19436. [CrossRef]

39. Greenland, C.; Shnier, A.; Rajendran, S.K.; Smith, J.A.; Game, O.S.; Wamwangi, D.; Turnbull, G.A.; Samuel, I.D.W.; Billing, D.G.; Lidzey, D.G. Correlating Phase Behavior with Photophysical Properties in Mixed-Cation Mixed-Halide Perovskite Thin Films. Adv. Energy Mater. 2019, 10, 4. [CrossRef]

40. Liu, Y.; Lu, H.; Niu, J.; Zhang, H.; Lou, S.; Gao, C.; Zhan, Y.; Zhang, X.; Jin, Q.; Zheng, L. Temperature-dependent photoluminescence spectra and decay dynamics of MAPbBr3 and MAPbI3 thin films. AIP Adv. 2018, 8, 095108. [CrossRef]

41. Tan, M.; Chen, B.; Zhang, Y.; Ni, M.; Wang, W.; Zhang, H.; Zhou, Q.; Bao, Y.; Wang, Y. Temperature-Dependent Dynamic Carrier Process of FAPbI3 Nanocrystals' Film. J. Phys. Chem. C 2020, 124, 5093-5098. [CrossRef]

42. Gélvez-Rueda, M.C.; Renaud, N.; Grozema, F.C. Temperature Dependent Charge Carrier Dynamics in Formamidinium Lead Iodide Perovskite. J. Phys. Chem. C 2017, 121, 23392-23397. [CrossRef] [PubMed]

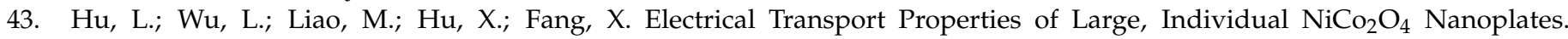
Adv. Funct. Mater. 2012, 22, 998-1004. [CrossRef]

44. Li, L.; Fang, X.; Zhai, T.; Liao, M.; Gautam, U.K.; Wu, X.; Koide, Y.; Bando, Y.; Golberg, D. Electrical Transport and HighPerformance Photoconductivity in Individual $\mathrm{ZrS}_{2}$ Nanobelts. Adv. Mater. 2010, 22, 4151-4156. [CrossRef] [PubMed] 
45. Fabini, D.H.; Stoumpos, C.C.; Laurita, G.; Kaltzoglou, A.; Kontos, A.G.; Falaras, P.; Kanatzidis, M.G.; Seshadri, R. Reentrant Structural and Optical Properties and Large Positive Thermal Expansion in Perovskite Formamidinium Lead Iodide. Angew. Chem. Int. Ed. Engl. 2016, 55, 15392-15396. [CrossRef] [PubMed]

46. Zhang, X.; Bi, S.; Zhou, J.; You, S.; Zhou, H.; Zhang, Y.; Tang, Z. Temperature-dependent charge transport in solu-tion-processed perovskite solar cells with tunable trap concentration and charge recombination. J. Mater. Chem. C 2017, 5, 9376-9382. [CrossRef]

47. Amani, M.; Tan, C.; Zhang, G.; Zhao, C.; Bullock, J.; Song, X.; Kim, H.; Shrestha, V.R.; Gao, Y.; Crozier, K.B.; et al. SolutionSynthesized High-Mobility Tellurium Nanoflakes for Short-Wave Infrared Photodetectors. ACS Nano 2018, 12, $7253-7263$. [CrossRef]

48. Cao, J.; Zou, Y.; Gong, X.; Gou, P.; Qian, J.; Qian, R.; An, Z. Double-layer heterostructure of graphene/carbon nanotube films for highly efficient broadband photodetector. Appl. Phys. Lett. 2018, 113, 061112. [CrossRef]

49. Zhang, G.; Amani, M.; Chaturvedi, A.; Tan, C.; Bullock, J.; Song, X.; Kim, H.; Lien, D.-H.; Scott, M.C.; Zhang, H.; et al. Optical and electrical properties of two-dimensional palladium diselenide. Appl. Phys. Lett. 2019, 114, 253102. [CrossRef]

50. Rath, A.K.; De Arquer, F.P.G.; Stavrinadis, A.; Lasanta, T.; Bernechea, M.; Diedenhofen, S.L.; Konstantatos, G. Remote Trap Passivation in Colloidal Quantum Dot Bulk Nano-heterojunctions and Its Effect in Solution-Processed Solar Cells. Adv. Mater. 2014, 26, 4741-4747. [CrossRef]

51. Wang, Q.; Wen, Y.; Yao, F.; Huang, Y.; Wang, Z.; Li, M.; Zhan, X.; Xu, K.; Wang, F.; Wang, F.; et al. BN-Enabled Epitaxy of Pb1-xSnxSe Nanoplates on $\mathrm{SiO}_{2}$ /Si for High-Performance Mid-Infrared Detection. Small 2015, 11, 5388-5394. [CrossRef]

52. Ramakrishnegowda, N.; Knoche, D.S.; Mühlenbein, L.; Lotnyk, A.; Bhatnagar, A. Bulk-Controlled Photovoltaic Effect in Nanometer-Thick Ferroelectric $\mathrm{Pb}(\mathrm{Zr0.2Ti0.8)O3} \mathrm{Thin} \mathrm{Films} \mathrm{and} \mathrm{the} \mathrm{Role} \mathrm{of} \mathrm{Domain} \mathrm{Walls.} \mathrm{ACS} \mathrm{Appl.} \mathrm{Nano} \mathrm{Mater.} \mathrm{2020,} \mathrm{3,}$ 11881-11888. [CrossRef]

53. Ackerman, M.M.; Tang, X.; Guyot-Sionnest, P. Fast and Sensitive Colloidal Quantum Dot Mid-Wave Infrared Photo-detectors ACS Nano 2018, 12, 7264-7271. [CrossRef]

54. Tong, J.; Tobing, L.Y.M.; Qiu, S.; Zhang, D.H.; Perera, A.G.U. Room temperature plasmon-enhanced InAs0.91Sb0.09-based heterojunctionn-i-pmid-wave infrared photodetector. Appl. Phys. Lett. 2018, 113, 011110. [CrossRef]

55. Zou, Y.; Holmes, R.J. Temperature-Dependent Bias Poling and Hysteresis in Planar Organo-Metal Halide Perovskite Photovoltaic Cells. Adv. Energy Mater. 2016, 6, 7. [CrossRef]

56. Fujiwara, H.; Fujimoto, S.; Tamakoshi, M.; Kato, M.; Kadowaki, H.; Miyadera, T.; Tampo, H.; Chikamatsu, M.; Shibata, H. Determination and interpretation of the optical constants for solar cell materials. Appl. Surf. Sci. 2017, 421, 276-282. [CrossRef]

57. Hadke, S.H.; Levcenko, S.; Lie, S.; Hages, C.J.; Márquez, J.A.; Unold, T.; Wong, L.H. Synergistic Effects of Double Cation Substitution in Solution-Processed CZTS Solar Cells with over 10\% Efficiency. Adv. Energy Mater. 2018, 8, 32. [CrossRef]

58. Tan, M.; Hu, C.; Lan, Y.; Khan, J.; Deng, H.; Yang, X.; Wang, P.; Yu, X.; Lai, J.; Song, H. 2D Lead Dihalides for High-Performance Ultraviolet Photodetectors and their Detection Mechanism Investigation. Small 2017, 13, 47. [CrossRef] [PubMed]

59. Zhang, H.; Li, Z.; Qian, J.; Guan, Q.; Du, X.; Cui, Y.; Zhang, J. Temperature-dependent photovoltaic characterization of a CdTe/CdSe nanocrystal's solar cell. Electron. Mater. Lett. 2014, 10, 433-437. [CrossRef]

60. Kask, E.; Krustok, J.; Giraldo, S.; Neuschitzer, M.; López-Marino, S.; Saucedo, E. Temperature dependent electrical characterization of thin film Cu2ZnSnSe4solar cells. J. Phys. D Appl. Phys. 2016, 49, 085101. [CrossRef]

61. Plis, E.; Myers, S.; Kutty, M.N.; Mailfert, J.; Smith, E.P.; Johnson, S.; Krishna, S. Lateral diffusion of minority carriers in InAsSb-based nBn detectors. Appl. Phys. Lett. 2010, 97, 123503. [CrossRef]

62. Schuler-Sandy, T.; Myers, S.; Klein, B.; Gautam, N.; Ahirwar, P.; Tian, Z.-B.; Rotter, T.; Balakrishnan, G.; Plis, E.; Krishna, S. Gallium free type II InAs/InAsxSb1-x superlattice photodetectors. Appl. Phys. Lett. 2012, 101, 071111. [CrossRef]

63. Reininger, P.; Zederbauer, T.; Schwarz, B.; Detz, H.; MacFarland, D.; Andrews, A.M.; Schrenk, W.; Strasser, G. InAs/AlAsSb based quantum cascade detector. Appl. Phys. Lett. 2015, 107, 081107. [CrossRef]

64. Rogalski, A.; Martyniuk, P.; Kopytko, M. InAs/GaSb type-II superlattice infrared detectors: Future prospect. Appl. Phys. Rev. 2017, 4, 031304. [CrossRef]

65. Rogalski, A.; Martyniuk, P.; Kopytko, M.; Madejczyk, P.; Krishna, S. InAsSb-Based Infrared Photodetectors: Thirty Years Later On. Sensors 2020, 20, 7047. [CrossRef] [PubMed]

66. Ting, D.Z.; Rafol, S.B.; Khoshakhlagh, A.; Soibel, A.; Keo, S.A.; Fisher, A.M.; Pepper, B.J.; Hill, C.J.; Gunapala, S.D. InAs/InAsSb Type-II Strained-Layer Superlattice Infrared Photodetectors. Micromachines 2020, 11, 958. [CrossRef] [PubMed]

67. Qu, T.L.; Zhao, Y.G.; Xie, D.; Shi, J.P.; Chen, Q.P.; Ren, T.L. Resistance switching and white-light photovoltaic effects in $\mathrm{BiFeO}_{3} / \mathrm{Nb}_{-}$ $\mathrm{SrTiO}_{3}$ heterojunctions. Appl. Phys. Lett. 2011, 98, 173507. [CrossRef]

68. Yi, H.T.; Choi, T.; Choi, S.G.; Oh, Y.S.; Cheong, S.-W. Mechanism of the Switchable Photovoltaic Effect in Ferroelectric BiFeO 3 . Adv. Mater. 2011, 23, 3403-3407. [CrossRef] [PubMed]

69. Li, H.; Jin, K.X.; Yang, S.H.; He, M.; Luo, B.; Wang, J.Y.; Chen, C.L.; Wu, T. Ultraviolet photovoltaic effect in $\mathrm{BiFeO}_{3} / \mathrm{Nb}^{-\mathrm{SrTiO}} 3$ heterostructure. J. Appl. Phys. 2012, 112, 083506. [CrossRef]

70. Bhatnagar, A.; Chaudhuri, A.R.; Kim, Y.H.; Hesse, D.; Alexe, M. Role of domain walls in the abnormal photovoltaic effect in $\mathrm{BiFeO}_{3}$. Nat. Commun. 2013, 4, 2835. [CrossRef]

71. Kim, D.J.; Alexe, M. Bulk photovoltaic effect in monodomain $\mathrm{BiFeO}_{3}$ thin films. Appl. Phys. Lett. 2017, 110, 183902. [CrossRef]

72. Buscema, M.; Island, J.O.; Groenendijk, D.J.; Blanter, S.I.; Steele, G.A.; van der Zant, H.S.; Castellanos-Gomez, A. Photocurrent generation with two-dimensional van der Waals semiconductors. Chem. Soc. Rev. 2015, 44, 3691-3718. [CrossRef] [PubMed] 
73. Xu, K.; Zhou, W.; Ning, Z. Integrated Structure and Device Engineering for High Performance and Scalable Quantum Dot Infrared Photodetectors. Small 2020, 16, e2003397. [CrossRef] [PubMed]

74. Mogera, U.; Walia, S.; Bannur, B.; Gedda, M.; Kulkarni, G.U. Intrinsic Nature of Graphene Revealed in Temperature-Dependent Transport of Twisted Multilayer Graphene. J. Phys. Chem. C 2017, 121, 13938-13943. [CrossRef]

75. Chusnutdinow, S.; Szot, M.; Wojtowicz, T.; Karczewski, G. PbSe/CdTe single quantum well infrared detectors. AIP Adv. 2017, 7, 035111. [CrossRef]

76. Kwon, J.; Kim, S.; Lee, J.; Park, C.; Kim, O.; Xu, B.; Bae, J.; Kang, S. Uncooled Short-Wave Infrared Sensor Based on PbS Quantum Dots Using ZnO NPs. Nanomaterials 2019, 9, 926. [CrossRef]

77. Chaudhuri, T.K.; Ghediya, P.R.; Patel, M.H. Dark and photoconductivity of PbS/polystyrene nanocomposite films from 77 to 300 K. Surf. Interfaces 2020, 20, 100580. [CrossRef]

78. Huang, M.; Wang, M.; Chen, C.; Ma, Z.; Li, X.; Han, J.; Wu, Y. Broadband Black-Phosphorus Photodetectors with High Responsivity. Adv. Mater. 2016, 28, 3481-3485. [CrossRef]

79. Zhang, B.Y.; Liu, T.; Meng, B.; Li, X.; Liang, G.; Hu, X.; Wang, Q.J. Broadband high photoresponse from pure monolayer graphene photodetector. Nat. Commun. 2013, 4, 1811. [CrossRef]

80. Pradhan, A.; Roy, A.; Tripathi, S.; Som, A.; Sarkar, D.; Mishra, J.K.; Roy, K.; Pradeep, T.; Narayanan, R.; Ghosh, A. Ultra-high sensitivity infra-red detection and temperature effects in a graphene-tellurium nanowire binary hybrid. Nanoscale 2017, 9 , 9284-9290. [CrossRef]

81. Ahmadi, E.; Asgari, A. Modeling of the infrared photodetector based on multi layer armchair graphene nanoribbons. J. Appl. Phys. 2013, 113, 093106. [CrossRef]

82. Yu, X.; Li, Y.; Hu, X.; Zhang, D.; Tao, Y.; Liu, Z.; He, Y.; Haque, A.; Liu, Z.; Wu, T.; et al. Narrow bandgap oxide nanoparticles coupled with graphene for high performance mid-infrared photodetection. Nat. Commun. 2018, 9, 1-8. [CrossRef] [PubMed]

83. Sun, D.; Aivazian, G.; Jones, A.M.; Ross, J.S.; Yao, W.; Cobden, D.H.; Xu, X. Ultrafast hot-carrier-dominated photocurrent in graphene. Nat. Nanotechnol. 2012, 7, 114-118. [CrossRef]

84. Dastgeer, G.; Khan, M.F.; Nazir, G.; Afzal, A.M.; Aftab, S.; Naqvi, B.A.; Cha, J.; Min, K.A.; Jamil, Y.; Jung, J.; et al. Temperature-Dependent and Gate-Tunable Rectification in a Black Phosphorus/WS2 van der Waals Heterojunc-tion Diode. ACS Appl. Mater. Interfaces 2018, 10, 13150-13157. [CrossRef] [PubMed]

85. Wang, L.; Liu, C.; Chen, X.; Zhou, J.; Hu, W.; Wang, X.; Li, J.; Tang, W.; Yu, A.; Wang, S.-W.; et al. Toward Sensitive RoomTemperature Broadband Detection from Infrared to Terahertz with Antenna-Integrated Black Phosphorus Photoconductor. Adv. Funct. Mater. 2017, 27. [CrossRef]

86. Tian, B.; Zheng, X.; Kempa, T.J.; Fang, Y.; Yu, N.; Yu, G.; Huang, J.; Lieber, C.M.; Dusastre, V. Coaxial silicon nanowires as solar cells and nanoelectronic power sources. Mater. Sustain. Energy 2010, 449, 58-62. [CrossRef]

87. Xu, J.; Chang, Y.; Gan, L.; Ma, Y.; Zhai, T. Ultrathin Single-Crystalline Boron Nanosheets for Enhanced Electro-Optical Performances. Adv. Sci. 2015, 2, 1500023. [CrossRef]

88. Xiang, D.; Liu, T.; Wang, J.; Wang, P.; Wang, L.; Zheng, Y.; Wang, Y.; Gao, J.; Ang, K.W.; Eda, G.; et al. Anomalous Broadband Spectrum Photodetection in 2D Rhenium Disulfide Transistor. Adv. Opt. Mater. 2019, 7, 1901115. [CrossRef]

89. Mak, K.F.; Shan, J. Photonics and optoelectronics of 2D semiconductor transition metal dichalcogenides. Nat. Photonics 2016, 10, 216-226. [CrossRef]

90. Killilea, N.; Wu, M.; Sytnyk, M.; Yousefi Amin, A.A.; Mashkov, O.; Spiecker, E.; Heiss, W. Pushing PbS/Metal-Halide-Perovskite Core/Epitaxial-Ligand-Shell Nanocrystal Photodetectors beyond $3 \mu \mathrm{m}$ Wavelength. Adv. Funct. Mater. 2019, $29,1807964$. [CrossRef]

91. Gilmore, R.H.; Winslow, S.W.; Lee, E.M.Y.; Ashner, M.N.; Yager, K.G.; Willard, A.P.; Tisdale, W.A. Inverse Temperature Dependence of Charge Carrier Hopping in Quantum Dot Solids. ACS Nano 2018, 12, 7741-7749. [CrossRef] [PubMed]

92. Chusnutdinow, S.; Schreyeck, S.; Kret, S.; Kazakov, A.; Karczewski, G. Room temperature infrared detectors made of PbTe/CdTe multilayer composite. Appl. Phys. Lett. 2020, 117, 072102. [CrossRef]

93. Speirs, M.J.; Dirin, D.N.; Abdu-Aguye, M.; Balazs, D.M.; Kovalenko, M.V.; Loi, M.A. Temperature dependent be-haviour of lead sulfide quantum dot solar cells and films. Energy Environ. Sci. 2016, 9, 2916-2924. [CrossRef]

94. Liu, C.-C.; Hao, F.-X.; Yin, Y.-W.; Li, X.-G. Photovoltaic effect and photo-assisted diode behavior in $\mathrm{Pt} / \mathrm{BiFeO}_{3} / \mathrm{Nb}^{-\mathrm{doped} \mathrm{SrTiO}} 3$ heterojunction. Acta Phys. Sin. 2020, 69, 127301. [CrossRef]

95. Meggle, F.; Viret, M.; Kreisel, J.; Kuntscher, C.A. Temperature-dependent photo-response in multiferroic $\mathrm{BiFeO}_{3}$ revealed by transmission measurements. J. Appl. Phys. 2019, 125, 114104. [CrossRef]

96. Ma, N.; Yang, Y. Enhanced self-powered UV photoresponse of ferroelectric $\mathrm{BaTiO}_{3}$ materials by pyroelectric effect. Nano Energy 2017, 40, 352-359. [CrossRef]

97. Ji, Y.; Gao, T.; Wang, Z.L.; Yang, Y. Configuration design of $\mathrm{BiFeO}_{3}$ photovoltaic devices for self-powered electronic watch. Nano Energy 2019, 64, 64. [CrossRef]

98. Ortiz-Quiñonez, J.L.; Díaz, D.; Zumeta-Dubé, I.; Arriola-Santamaría, H.; Betancourt, I.; Santiago-Jacinto, P.; Nava-Etzana, N. Easy Synthesis of High-Purity $\mathrm{BiFeO}_{3}$ Nanoparticles: New Insights Derived from the Structural, Optical, and Magnetic Characterization. Inorg. Chem. 2013, 52, 10306-10317. [CrossRef]

99. Song, K.; Ma, N.; Yang, Y. Enhanced Self-Powered UV Photoresponse of Ferroelectric PZT Materials by Pyroelectric Effect. Adv. Mater. Technol. 2017, 2, 12. [CrossRef] 
100. Kinch, M.A. The Future of Infrared; III-Vs or HgCdTe? J. Electron. Mater. 2015, 44, 2969-2976. [CrossRef]

101. Zhu, L.; Deng, Z.; Huang, J.; Guo, H.; Chen, L.; Lin, C.; Chen, B. Low frequency noise-dark current correlations in HgCdTe infrared photodetectors. Opt. Express 2020, 28, 23660. [CrossRef] [PubMed]

102. Tang, X.; Ackerman, M.M.; Guyot-Sionnest, P. Thermal Imaging with Plasmon Resonance Enhanced HgTe Colloidal Quantum Dot Photovoltaic Devices. ACS Nano 2018, 12, 7362-7370. [CrossRef]

103. Shao, S.; Liu, J.; Fang, H.-H.; Qiu, L.; ten Brink, G.H.; Hummelen, J.C.; Koster, L.J.A.; Loi, M.A. Efficient Perovskite Solar Cells over a Broad Temperature Window: The Role of the Charge Carrier Extraction. Adv. Energy Mater. 2017, 7, 1701305. [CrossRef]

104. Leong, W.L.; Ooi, Z.-E.; Sabba, D.; Yi, C.; Zakeeruddin, S.M.; Graetzel, M.; Gordon, J.M.; Katz, E.A.; Mathews, N. Identifying Fundamental Limitations in Halide Perovskite Solar Cells. Adv. Mater. 2016, 28, 2439-2445. [CrossRef] [PubMed]

105. Varshni, Y. Temperature dependence of the energy gap in semiconductors. Physica 1967, 34, 149-154. [CrossRef]

106. Sze, S.M.; Ng, K.K. Physics and Properties of Semiconductors-A Review. In Physics of Semiconductor Devices; John Wiley \& Sons: Hoboken, NJ, USA, 2006; pp. 5-75.

107. Mott, N.F.; Davis, E.A.; Weiser, K. Electronic Processes in Non-Crystalline Materials. Phys. Today 1972, 25, 55. [CrossRef]

108. Mott, N.F.; Mott, N.F. Conduction in non-crystalline materials. Philos. Mag. 1969, 19, 835-852. [CrossRef]

109. Johnston, M.B.; Herz, L.M. Hybrid Perovskites for Photovoltaics: Charge-Carrier Recombination, Diffusion, and Radiative Efficiencies. Acc. Chem. Res. 2016, 49, 146-154. [CrossRef]

110. Yardimci, N.T.; Jarrahi, M. Nanostructure-Enhanced Photoconductive Terahertz Emission and Detection. Small 2018, 14, e1802437. [CrossRef]

111. Zhou, Y.; Zhou, Z.; Chen, M.; Zong, Y.; Huang, J.; Pang, S.; Padture, N.P. Doping and alloying for improved perovskite solar cells. J. Mater. Chem. A 2016, 4, 17623-17635. [CrossRef]

112. Hardin, B.E.; Snaith, H.J.; McGehee, M.D. The renaissance of dye-sensitized solar cells. Nat. Photon. 2012, 6, 162-169. [CrossRef]

113. Flemban, T.H.; Haque, M.A.; Ajia, I.; Alwadai, N.; Mitra, S.; Wu, T.; Roqan, I.S. A Photodetector Based on p-Si/n-ZnO Nanotube Heterojunctions with High Ultraviolet Responsivity. ACS Appl. Mater. Interfaces 2017, 9, 37120-37127. [CrossRef] [PubMed]

114. Fang, H.-H.; Raissa, R.; Abdu-Aguye, M.; Adjokatse, S.; Blake, G.R.; Even, J.; Loi, M.A. Photophysics of Organ-ic-Inorganic Hybrid Lead Iodide Perovskite Single Crystals. Adv. Funct. Mater. 2015, 25, 2378-2385. [CrossRef]

115. Wu, K.; Bera, A.; Ma, C.; Du, Y.; Yang, Y.; Li, L.; Wu, T. Temperature-dependent excitonic photoluminescence of hybrid organometal halide perovskite films. Phys. Chem. Chem. Phys. 2014, 16, 22476-22481. [CrossRef]

116. Diroll, B.T.; Guo, P.; Schaller, R.D. Unique Optical Properties of Methylammonium Lead Iodide Nanocrystals below the Bulk Tetragonal-Orthorhombic Phase Transition. Nano Lett. 2018, 18, 846-852. [CrossRef]

117. Fang, H.H.; Wang, F.; Adjokatse, S.; Zhao, N.; Even, J.; Antonietta Loi, M. Photoexcitation dynamics in solu-tion-processed formamidinium lead iodide perovskite thin films for solar cell applications. Light Sci. Appl. 2016, 5, e16056. [CrossRef] [PubMed]

118. Parrott, E.S.; Green, T.; Milot, R.L.; Johnston, M.B.; Snaith, H.J.; Herz, L.M. Interplay of Structural and Optoelectronic Properties in Formamidinium Mixed Tin-Lead Triiodide Perovskites. Adv. Funct. Mater. 2018, 28, 33. [CrossRef]

119. Zheng, H.; Dai, J.; Duan, J.; Chen, F.; Zhu, G.; Wang, F.; Xu, C. Temperature-dependent photoluminescence properties of mixed-cation methylammonium-formamidium lead iodide [HC(NH2)2]x[CH3NH3]1-xPbI3 perovskite nanostructures. J. Mater. Chem. C 2017, 5, 12057-12061. [CrossRef]

120. Szendrei, K.; Speirs, M.; Gomulya, W.; Jarzab, D.; Manca, M.; Mikhnenko, O.V.; Yarema, M.; Kooi, B.J.; Heiss, W.; Loi, M.A Exploring the Origin of the Temperature-Dependent Behavior of PbS Nanocrystal Thin Films and Solar Cells. Adv. Funct. Mater. 2012, 22, 1598-1605. [CrossRef]

121. Olkhovets, A.; Hsu, R.-C.; Lipovskii, A.; Wise, F.W. Size-Dependent Temperature Variation of the Energy Gap in Lead-Salt Quantum Dots. Phys. Rev. Lett. 1998, 81, 3539-3542. [CrossRef]

122. Amani, M.; Regan, E.; Bullock, J.; Ahn, G.H.; Javey, A. Mid-Wave Infrared Photoconductors Based on Black Phosphorus-Arsenic Alloys. ACS Nano 2017, 11, 11724-11731. [CrossRef]

123. Villegas, C.E.P.; Rodin, A.S.; Carvalho, A.; Rocha, A.R. Two-dimensional exciton properties in monolayer semiconducting phosphorus allotropes. Phys. Chem. Chem. Phys. 2016, 18, 27829-27836. [CrossRef]

124. Wang, F.; Wang, Z.; Xu, K.; Wang, F.; Wang, Q.; Huang, Y.; Yin, L.; He, J. Tunable GaTe-MoS2 van der Waals p-n Junctions with Novel Optoelectronic Performance. Nano Lett. 2015, 15, 7558-7566. [CrossRef]

125. Singh, D.K.; Pant, R.; Roul, B.; Chowdhury, A.M.; Nanda, K.K.; Krupanidhi, S.B. Temperature-Dependent Electrical Transport and Optoelectronic Properties of $\mathrm{SnS}_{2} / \mathrm{p}$-Si Heterojunction. ACS Appl. Electron. Mater. 2020, 2, 2155-2163. [CrossRef]

126. Wu, D.; Li, J.; Dehzangi, A.; Razeghi, M. Mid-wavelength infrared high operating temperature pBn photodetectors based on type-II InAs/InAsSb superlattice. AIP Adv. 2020, 10, 025018. [CrossRef]

127. Chen, R.-S.; Yang, T.-H.; Chen, H.-Y.; Chen, L.-C.; Chen, K.-H.; Yang, Y.-J.; Su, C.-H.; Lin, C.-R. High-gain photocon-ductivity in semiconducting InN nanowires. Appl. Phys. Lett. 2009, 95, 162112. [CrossRef]

128. Zheng, K.; Luo, L.-B.; Zhang, T.-F.; Liu, Y.-H.; Yu, Y.-Q.; Lu, R.; Qiu, H.-L.; Li, Z.-J.; Huang, J.C.A. Optoelectronic characteristics of a near infrared light photodetector based on a topological insulator $\mathrm{Sb}_{2} \mathrm{Te}_{3}$ film. J. Mater. Chem. C 2015, 3, 9154-9160. [CrossRef]

129. Li, L.; Wang, W.; Gan, L.; Zhou, N.; Zhu, X.; Zhang, Q.; Li, H.; Tian, M.; Zhai, T. Ternary Ta 2 NiSe $_{5}$ Flakes for a High-Performance Infrared Photodetector. Adv. Funct. Mater. 2016, 26, 8281-8289. [CrossRef]

130. Zhou, X.; Hu, X.; Zhou, S.; Zhang, Q.; Li, H.; Zhai, T. Ultrathin $2 \mathrm{D}$ GeSe2 Rhombic Flakes with High Anisotropy Realized by Van der Waals Epitaxy. Adv. Funct. Mater. 2017, 27, 1703858. [CrossRef] 
131. Park, J.; Lee, E.; Lee, K.W.; Lee, C.E. Electrical transport and quasipersistent photocurrent in vanadium oxide nanowire networks. Appl. Phys. Lett. 2006, 89, 183114. [CrossRef]

132. Bullot, J.; Gallais, O.; Gauthier, M.; Livage, J. Semiconducting properties of amorphous $\mathrm{V}_{2} \mathrm{O}_{5}$ layers deposited from gels. Appl. Phys. Lett. 1980, 36, 986. [CrossRef]

133. Chen, M.; Lan, X.; Tang, X.; Wang, Y.; Hudson, M.H.; Talapin, D.V.; Guyot-Sionnest, P. High Carrier Mobility in HgTe Quantum Dot Solids Improves Mid-IR Photodetectors. ACS Photon. 2019, 6, 2358-2365. [CrossRef]

134. Suleiman, A.A.; Huang, P.; Jin, B.; Jiang, J.; Zhang, X.; Zhou, X.; Zhai, T. Space-Confined Growth of 2D InI Showing High Sensitivity in Photodetection. Adv. Electron. Mater. 2020, 6, 6. [CrossRef]

135. Siontas, S.; Wang, H.; Li, D.; Zaslavsky, A.; Pacifici, D. Broadband visible-to-telecom wavelength germanium quantum dot photodetectors. Appl. Phys. Lett. 2018, 113, 181101. [CrossRef]

136. Radisavljevic, B.; Kis, A. Mobility engineering and a metal-insulator transition in monolayer MoS2. Nat. Mater. 2013, 12, 815-820. [CrossRef]

137. Jia, B.W.; Tan, K.H.; Loke, W.K.; Wicaksono, S.; Lee, K.H.; Yoon, S.F. Monolithic Integration of InSb Photodetector on Silicon for Mid-Infrared Silicon Photonics. ACS Photon. 2018, 5, 1512-1520. [CrossRef]

138. Ravikumar, A.P.; De Jesus, J.; Tamargo, M.C.; Gmachl, C.F. High performance, room temperature, broadband II-VI quantum cascade detector. Appl. Phys. Lett. 2015, 107, 141105. [CrossRef]

139. Sun, Y.; Wang, G.; Han, X.; Xiang, W.; Jiang, D.; Jiang, Z.; Hao, H.; Lv, Y.; Guo, C.; Xu, Y.; et al. $320 \times 256$ high operating temperature mid-infrared focal plane arrays based on type-II InAs/GaSb superlattice. Superlattices Microstruct. 2017, 111, 783-788. [CrossRef]

140. Zhou, J.; Lei, N.; Zhou, H.; Zhang, Y.; Tang, Z.; Jiang, L.; Zhou, J. Understanding the temperature-dependent charge transport, structural variation and photoluminescent properties in methylammonium lead halide perovskite single crystals. J. Mater. Chem. C 2018, 6, 6556-6564. [CrossRef]

141. Maimon, S.; Wicks, G.W. nBn detector, an infrared detector with reduced dark current and higher operating temperature. Appl. Phys. Lett. 2006, 89, 151109. [CrossRef]

142. Marozas, B.T.; Hughes, W.D.; Du, X.; Sidor, D.E.; Savich, G.R.; Wicks, G.W. Surface dark current mechanisms in III-V infrared photodetectors [Invited]. Opt. Mater. Express 2018, 8, 1419-1424. [CrossRef]

143. Wang, P.; Xia, H.; Li, Q.; Wang, F.; Zhang, L.; Li, T.; Martyniuk, P.; Rogalski, A.; Hu, W. Sensing Infrared Photons at Room Temperature: From Bulk Materials to Atomic Layers. Small 2019, 15, e1904396. [CrossRef]

144. Chen, B.; Yuan, J.; Holmes, A.L. Dark current modeling of InP based SWIR and MWIR InGaAs/GaAsSb type-II MQW photodiodes. Opt. Quantum Electron. 2012, 45, 271-277. [CrossRef]

145. Olson, B.V.; Shaner, E.A.; Kim, J.K.; Klem, J.F.; Hawkins, S.D.; Murray, L.M.; Prineas, J.P.; Flatte, M.E.; Boggess, T.F. Time-resolved optical measurements of minority carrier recombination in a mid-wave infrared InAsSb alloy and InAs/InAsSb superlattice. Appl. Phys. Lett. 2012, 101, 092109. [CrossRef]

146. Izumi, S.; Shaban, M.; Promros, N.; Nomoto, K.; Yoshitake, T. Near-infrared photodetection of $\beta$-FeSi $2 / \mathrm{Si}$ heterojunction photodiodes at low temperatures. Appl. Phys. Lett. 2013, 102, 32107. [CrossRef]

147. Chen, M.; Lu, H.; Abdelazim, N.M.; Zhu, Y.; Wang, Z.; Ren, W.; Kershaw, S.V.; Rogach, A.L.; Zhao, N. Mercury Tel-luride Quantum Dot Based Phototransistor Enabling High-Sensitivity Room-Temperature Photodetection at $2000 \mathrm{~nm}$. ACS Nano 2017, 11, 5614-5622. [CrossRef]

148. Qiao, S.; Liu, J.; Liu, Y.; Yan, G.; Wang, S.; Fu, G. Large Near-Infrared Lateral Photovoltaic Effect of ITO/Si Structure Observed at Low Temperature. IEEE Trans. Electron Devices 2016, 63, 3574-3577. [CrossRef]

149. Guyot-Sionnest, P.; Roberts, J.A. Background limited mid-infrared photodetection with photovoltaic HgTe colloidal quantum dots. Appl. Phys. Lett. 2015, 107, 253104. [CrossRef]

150. Jiang, Z.; Hu, W.; Mo, C.; Liu, Y.; Zhang, W.; You, G.; Wang, L.; Atalla, M.R.M.; Zhang, Y.; Liu, J.; et al. Ultra-sensitive tandem colloidal quantum-dot photodetectors. Nanoscale 2015, 7, 16195-16199. [CrossRef]

151. Wang, M.; García-Hemme, E.; Berencén, Y.; Hübner, R.; Xie, Y.; Rebohle, L.; Xu, C.; Schneider, H.; Helm, M.; Zhou, S. Silicon-Based Intermediate-Band Infrared Photodetector Realized by Te Hyperdoping. Adv. Opt. Mater. 2021, 9. [CrossRef]

152. Wu, D.; Dehzangi, A.; Li, J.; Razeghi, M. High performance Zn-diffused planar mid-wavelength infrared type-II InAs/InAs1-xSbx superlattice photodetector by MOCVD. Appl. Phys. Lett. 2020, 116, 161108. [CrossRef]

153. Tang, S.-F.; Lin, S.-Y.; Lee, S.-C. Near-room-temperature operation of an InAs/GaAs quantum-dot infrared photodetector. Appl. Phys. Lett. 2001, 78, 2428-2430. [CrossRef]

154. Shin, H.W.; Lee, S.J.; Kim, D.G.; Bae, M.-H.; Heo, J.; Choi, K.J.; Choi, W.J.; Choe, J.-W.; Shin, J.C. Short-wavelength infrared photodetector on Si employing strain-induced growth of very tall InAs nanowire arrays. Sci. Rep. 2015, 5, 10764. [CrossRef]

155. Gautam, N.; Myers, S.; Barve, A.V.; Klein, B.; Smith, E.P.; Rhiger, D.R.; Dawson, L.R.; Krishna, S. High operating temperature interband cascade midwave infrared detector based on type-II InAs/GaSb strained layer superlattice. Appl. Phys. Lett. 2012, 101, 021106. [CrossRef]

156. Lim, H.; Tsao, S.; Zhang, W.; Razeghi, M. High-performance InAs quantum-dot infrared photodetectors grown on InP substrate operating at room temperature. Appl. Phys. Lett. 2007, 90, 131112. [CrossRef]

157. Soibel, A.; Ting, D.Z.; Hill, C.J.; Fisher, A.M.; Hoglund, L.; Keo, S.A.; Gunapala, S.D. Mid-wavelength infrared InAsSb/InSb nBn detector with extended cut-off wavelength. Appl. Phys. Lett. 2016, 109, 103505. [CrossRef] 
158. Wang, X.-J.; Zhai, S.-Q.; Zhuo, N.; Liu, J.-Q.; Liu, F.-Q.; Liu, S.-M.; Wang, Z.-G. Quantum dot quantum cascade infrared photodetector. Appl. Phys. Lett. 2014, 104, 171108. [CrossRef]

159. Pham, T.; Du, W.; Conley, B.; Margetis, J.; Sun, G.; Soref, R.; Tolle, J.; Li, B.; Yu, S. Si-based Ge ${ }_{0.9} \mathrm{Sn}_{0.1}$ photodetector with peak responsivity of $2.85 \mathrm{~A} / \mathrm{W}$ and longwave cutoff at $2.4 \mu \mathrm{m}$. Electron. Lett. 2015, 51, 854-856. [CrossRef]

160. Sangwan, V.K.; Kang, J.; Lam, D.; Gish, J.T.; Wells, S.A.; Luxa, J.; Male, J.P.; Snyder, G.J.; Sofer, Z.; Hersam, M.C. Intrinsic carrier multiplication in layered Bi2O2Se avalanche photodiodes with gain bandwidth product exceeding 1 GHz. Nano Res. 2020, 1-6. [CrossRef]

161. Jena, A.K.; Kulkarni, A.; Miyasaka, T. Halide Perovskite Photovoltaics: Background, Status, and Future Prospects. Chem. Rev. 2019, 119, 3036-3103. [CrossRef] [PubMed]

162. Luo, D.; Su, R.; Zhang, W.; Gong, Q.; Zhu, R. Minimizing non-radiative recombination losses in perovskite solar cells. Nat. Rev. Mater. 2020, 5, 44-60. [CrossRef]

163. Taskesen, T.; Neerken, J.; Schoneberg, J.; Pareek, D.; Steininger, V.; Parisi, J.; Gütay, L. Device Characteristics of an $11.4 \%$ CZTSe Solar Cell Fabricated from Sputtered Precursors. Adv. Energy Mater. 2018, 8. [CrossRef]

164. Zhou, Q.; Wang, B.; Meng, R.; Zhou, J.; Xie, S.; Zhang, X.; Wang, J.; Yue, S.; Qin, B.; Zhou, H.; et al. Understanding TemperatureDependent Charge Extraction and Trapping in Perovskite Solar Cells. Adv. Funct. Mater. 2020, 30, 22. [CrossRef]

165. Li, R.; Peng, J.; Xu, Y.; Li, W.; Cui, L.; Li, Y.; Lin, Q. Pseudohalide Additives Enhanced Perovskite Photodetectors. Adv. Opt. Mater. 2021, 9. [CrossRef]

166. Yu, H.; Lu, H.; Xie, F.; Zhou, S.; Zhao, N. Native Defect-Induced Hysteresis Behavior in Organolead Iodide Perovskite Solar Cells. Adv. Funct. Mater. 2016, 26, 1411-1419. [CrossRef]

167. Wang, Y.; Yue, Y.; Yang, X.; Han, L. Toward Long-Term Stable and Highly Efficient Perovskite Solar Cells via Effective Charge Transporting Materials. Adv. Energy Mater. 2018, 8, 22. [CrossRef]

168. Poglitsch, A.; Weber, D. Dynamic disorder in methylammoniumtrihalogenoplumbates (II) observed by millimeter-wave spectroscopy. J. Chem. Phys. 1987, 87, 6373-6378. [CrossRef]

169. Fabini, D.H.; Siaw, T.A.; Stoumpos, C.C.; Laurita, G.; Olds, D.; Page, K.; Hu, J.G.; Kanatzidis, M.G.; Han, S.; Seshadri, R. Universal Dynamics of Molecular Reorientation in Hybrid Lead Iodide Perovskites. J. Am. Chem. Soc. 2017, 139, 16875-16884. [CrossRef] [PubMed]

170. Stoumpos, C.C.; Malliakas, C.D.; Kanatzidis, M.G. Semiconducting Tin and Lead Iodide Perovskites with Organic Cations: Phase Transitions, High Mobilities, and Near-Infrared Photoluminescent Properties. Inorg. Chem. 2013, 52, 9019-9038. [CrossRef]

171. Lou, X.; Yao, L.; Jin, S.; Sui, N.; Wang, W.; Kang, Z.; Zhou, Q.; Li, L.; Ni, M.; Zhang, H.; et al. Temperature-Dependent Ultrafast Spectral Response of FAPb(Br0.4I0.6)3 Nanocrystals. J. Phys. Chem. C 2021, 125, 1157-1166. [CrossRef]

172. Biewald, A.; Giesbrecht, N.; Bein, T.; Docampo, P.; Hartschuh, A.; Ciesielski, R. Temperature-Dependent Ambipolar Charge Carrier Mobility in Large-Crystal Hybrid Halide Perovskite Thin Films. ACS Appl. Mater. Interfaces 2019, 11, 20838-20844. [CrossRef] [PubMed]

173. Patel, J.B.; Lin, Q.; Zadvorna, O.; Davies, C.L.; Herz, L.M.; Johnston, M.B. Photocurrent Spectroscopy of Perovskite Solar Cells Over a Wide Temperature Range from 15 to 350 K. J. Phys. Chem. Lett. 2017, 9, 263-268. [CrossRef] [PubMed]

174. Chen, S.; Hou, Y.; Chen, H.; Richter, M.; Guo, F.; Kahmann, S.; Tang, X.; Stubhan, T.; Zhang, H.; Li, N.; et al. Exploring the Limiting Open-Circuit Voltage and the Voltage Loss Mechanism in Planar CH3NH3PbBr3Perovskite Solar Cells. Adv. Energy Mater. 2016, 6, 18. [CrossRef]

175. Tress, W.; Yavari, M.; Domanski, K.; Yadav, P.; Niesen, B.; Correa Baena, J.P.; Hagfeldt, A.; Graetzel, M. Interpretation and evolution of open-circuit voltage, recombination, ideality factor and subgap defect states during reversible light-soaking and irreversible degradation of perovskite solar cells. Energy Environ. Sci. 2018, 11, 151-165. [CrossRef]

176. Langevin, P. The recombination and mobilities of ions in gases. Ann. Chim. Phys. 1903, 28, 433-530.

177. Zhao, Y.; Zhu, K. Organic-inorganic hybrid lead halide perovskites for optoelectronic and electronic applications. Chem. Soc. Rev. 2016, 45, 655-689. [CrossRef]

178. Xiao, Z.; Yuan, Y.; Shao, Y.; Wang, Q.; Dong, Q.; Bi, C.; Sharma, P.; Gruverman, A.; Huang, J. Giant switchable photo-voltaic effect in organometal trihalide perovskite devices. Nat. Mater. 2014, 14, 193-198. [CrossRef]

179. Chen, H.W.; Sakai, N.; Ikegami, M.; Miyasaka, T. Emergence of Hysteresis and Transient Ferroelectric Response in Organo-Lead Halide Perovskite Solar Cells. J. Phys. Chem. Lett. 2015, 6, 164-169. [CrossRef]

180. Bryant, D.; Wheeler, S.; O'Regan, B.C.; Watson, T.; Barnes, P.R.F.; Worsley, D.; Durrant, J. Observable Hysteresis at Low Temperature in "Hysteresis Free" Organic-Inorganic Lead Halide Perovskite Solar Cells. J. Phys. Chem. Lett. 2015, 6, 3190-3194. [CrossRef]

181. Chen, Y.; Tan, S.; Li, N.; Huang, B.; Niu, X.; Li, L.; Sun, M.; Zhang, Y.; Zhang, X.; Zhu, C.; et al. Self-Elimination of Intrinsic Defects Improves the Low-Temperature Per-formance of Perovskite Photovoltaics. Joule 2020, 4, 1961-1976. [CrossRef]

182. Yang, Y.; Wang, Z.L. Hybrid energy cells for simultaneously harvesting multi-types of energies. Nano Energy 2015, 14, 245-256. [CrossRef]

183. Zhang, K.; Wang, Z.L.; Yang, Y. Enhanced P3HT/ZnO Nanowire Array Solar Cells by Pyro-phototronic Effect. ACS Nano 2016, 10, 10331-10338. [CrossRef]

184. Ma, N.; Yang, Y. Boosted photocurrent in ferroelectric $\mathrm{BaTiO}_{3}$ materials via two dimensional planar-structured contact configurations. Nano Energy 2018, 50, 417-424. [CrossRef] 
185. Zhang, K.; Wang, S.; Yang, Y. A One-Structure-Based Piezo-Tribo-Pyro-Photoelectric Effects Coupled Nanogenerator for Simultaneously Scavenging Mechanical, Thermal, and Solar Energies. Adv. Energy Mater. 2016, 7, 1601852. [CrossRef]

186. Ji, Y.; Zhang, K.; Yang, Y. A One-Structure-Based Multieffects Coupled Nanogenerator for Simultaneously Scavenging Thermal, Solar, and Mechanical Energies. Adv. Sci. 2018, 5, 1700622. [CrossRef]

187. Qi, J.; Ma, N.; Yang, Y. Photovoltaic-Pyroelectric Coupled Effect Based Nanogenerators for Self-Powered Photodetector System. Adv. Mater. Interfaces 2018, 5, 3. [CrossRef]

188. Zhang, K.; Yang, Y. Thermo-Phototronic Effect Enhanced InP/ZnO Nanorod Heterojunction Solar Cells for Self-Powered Wearable Electronics. Adv. Funct. Mater. 2017, 27, 1703331. [CrossRef]

189. Song, K.; Ma, N.; Mishra, Y.K.; Adelung, R.; Yang, Y. Achieving Light-Induced Ultrahigh Pyroelectric Charge Density Toward Self-Powered UV Light Detection. Adv. Electron. Mater. 2019, 5, 1. [CrossRef]

190. Zhao, R.; Ma, N.; Qi, J.; Mishra, Y.K.; Adelung, R.; Yang, Y. Optically Controlled Abnormal Photovoltaic Current Mod-ulation with Temperature in $\mathrm{BiFeO}_{3}$. Adv. Electron. Mater. 2019, 5, 1800791. [CrossRef]

191. Zhang, R.; Hummelgård, M.; Örtegren, J.; Olsen, M.; Andersson, H.; Yang, Y.; Olin, H. Human Body Constituted Tri-boelectric Nanogenerators as Energy Harvesters, Code Transmitters, and Motion Sensors. ACS Appl. Energ. Mater. 2018, 1, $2955-2960$. [CrossRef]

192. Zhao, K.; Ouyang, B.; Bowen, C.R.; Wang, Z.L.; Yang, Y. One-structure-based multi-effects coupled nanogenerators for flexible and self-powered multi-functional coupled sensor systems. Nano Energy 2020, 71, 104632. [CrossRef]

193. Ji, Y.; Wang, Y.; Yang, Y. Photovoltaic-Pyroelectric-Piezoelectric Coupled Effect Induced Electricity for Self-Powered Coupled Sensing. Adv. Electron. Mater. 2019, 5, 1900195. [CrossRef]

194. Chang, Y.; Wang, J.; Wu, F.; Tian, W.; Zhai, W. Structural Design and Pyroelectric Property of SnS/CdS Heterojunctions Contrived for Low-Temperature Visible Photodetectors. Adv. Funct. Mater. 2020, 30, 23. [CrossRef]

195. Peng, W.; Yu, R.; Wang, X.; Wang, Z.; Zou, H.; He, Y.; Wang, Z.L. Temperature dependence of pyro-phototronic effect on self-powered $\mathrm{ZnO} /$ perovskite heterostructured photodetectors. Nano Res. 2016, 9, 3695-3704. [CrossRef]

196. Dong, J.; Wang, Z.; Wang, X.; Wang, Z.L. Temperature dependence of the pyro-phototronic effect in self-powered p-Si/n-ZnO nanowires heterojuncted ultraviolet sensors. Nano Today 2019, 29, 100798. [CrossRef]

197. Ma, N.; Yang, Y. Boosted photocurrent via cooling ferroelectric BaTiO3 materials for self-powered $405 \mathrm{~nm}$ light detection. Nano Energy 2019, 60, 95-102. [CrossRef]

198. Yu, R.; Wang, X.; Wu, W.; Pan, C.; Bando, Y.; Fukata, N.; Hu, Y.; Peng, W.; Ding, Y.; Wang, Z.L. Temperature Dependence of the Piezophototronic Effect in CdS Nanowires. Adv. Funct. Mater. 2015, 25, 5277-5284. [CrossRef]

199. Wang, X.; Yu, R.; Peng, W.; Wu, W.; Li, S.; Wang, Z.L. Temperature Dependence of the Piezotronic and Piezophototronic Effects ina-axis GaN Nanobelts. Adv. Mater. 2015, 27, 8067-8074. [CrossRef] 